\title{
Paisajes racializados y fronteras identitarias en Costa Rica:relatos de viajeros y el ferrocarril al Caribe (1885-1930)*
}

\section{Resumen}

El artículo analiza diferentes textos de extranjeros, mayoritariamente estadounidenses -pero no solamente-, que en su mayoría visitan el país y que podríamos considerar como literatura de viaje, entre 1885 y 1930, con el objetivo de evaluar la narrativa generada en cuanto a los paisajes étnicos que se forjan al interior de la geografía estatal y nacional costarricense en la cual se imponía históricamente la ficción de una homogeneidad y blancura. En el estudio podemos descubrir cómo los autores foráneos ejecutan ese ejercicio de cartografía étnico-racial y, muy especialmente, en torno al itinerario del desplazamiento del ferrocarril entre Limón el puerto del Caribe- y San José - la capital, en el Valle central del país-.El flujo que se producía en el marco de la ruta ferroviaria permitía a los autores dibujar etnopaisajes o paisajes étnicos y, por ende, fronteras identitarias: un etnopaisaje homogéneo y estable -una supuesta homogeneidad cultural, lingüística y fenotípica- en el Valle Central y otro etnopaisaje más fluido y menos estable conformado por diversos grupos étnicos, pero especialmente de cuerpos afrocaribeños.

\section{Palabras clave}

Tesauro: paisaje; grupo étnico; geografía; tren; viaje; Costa Rica.

Referencia bibliográfica para citar este artículo: Soto-Quirós, Ronald. "Paisajes racializados y fronteras identitarias en Costa Rica: relatos de viajeros y el ferrocarril al Caribe (1885-1930". Anuario de Historia Regional y de las Fronteras 26.2 (2021): 317-357.

Fecha de recepción: 30/11/2020

Fecha de aceptación: 2/04/2021

Ronald Soto-Quirós: Doctor en Estudios Ibéricos e Iberoamericanos (historia) de la Université Bordeaux Montaigne. Máster en Historia y Civilizaciones de la Université Toulouse-Jean-Jaurès. Profesor investigador titular en la Université de Bordeaux e investigador en el laboratorio AMERIBER de la Université Bordeaux Montaigne. Código ORCID: 0000-0002-3312-4777. Correo electrónico: ronald.sotoquiros@u-bordeaux.fr

${ }^{*}$ El trabajo forma parte de las diferentes investigaciones del autor en el marco del centro Recherches Américanistes del laboratorio pluridisciplinario sobre la Península Ibérica y América Latina AMERIBER de la Université Bordeaux Montaigne. El centro focaliza actuamente sus estudios sobre la problemática de circulaciones y migraciones. 


\title{
Racialized Landscapes and Identity Borders: Traveler's Stories and the Railway to the Caribbean (1885-1930)
}

\begin{abstract}
The article analyzes different texts of foreigners, mostly -but not only-Americans, who mostly visited the country and that could be considered as travel literature, between 1885 and 1930, with the objective of evaluating the narrative generated regarding the ethnic landscapes that are forged within the Costa Rican state and national geography in which the fiction of homogeneity and whiteness was historically imposed. In this study, it is discovered how foreign authors carry out this exercise in ethnic-racial cartography, especially concerning the route of the railroad between Limón, the port of the Caribbean, and San José, the capital, in the country's Central Valley. The flow that took place within the framework of the railroad route allowed the authors to draw ethno-landscapes or ethnic territories and, therefore, identity borders: a homogeneous and stable ethno-landscape - a supposed cultural, linguistic, and phenotypical homogeneity and stable in the Central Valley-, and another more fluid and less stable ethno-landscape made up of diverse ethnic groups, but especially of Afro-Caribbean bodies.
\end{abstract}

Keywords

Tesauro: Landscape; Ethnic Group; Geography; Railway Transport; Travel; Costa Rica.

\section{Paisagens racializadas e fronteiras de identidade na Costa Rica: histórias de viajantes e a ferrovia para o Caribe (1885-1930)}

\section{Resumo}

O artigo analisa diferentes textos de estrangeiros, principalmente - mas não apenasamericanos, que visitam principalmente o país e que poderíamos considerar como literatura de viagem, entre 1885 e 1930, com o objetivo de avaliar a narrativa gerada em termos das paisagens étnicas que são forjadas dentro do estado costarriquenho e da geografia nacional na qual a ficção de uma homogeneidade e brancura foi historicamente imposta. No estudo é possivel descobrir como autores estrangeiros realizam este exercício de cartografia étnicoracial e, muito especialmente, em torno da rota do deslocamento da ferrovia entre Limón -o porto do Caribe-e San José - a capital, no vale central do país-. O fluxo que ocorreu no âmbito da rota ferroviária permitiu aos autores desenhar paisagens étnicas ou etnopaisagens e, portanto, fronteiras de identidade: uma paisagem étnica homogênea e estável-uma suposta homogeneidade cultural, linguística e fenotípica- no Vale Central e outra paisagem étnica mais fluida e menos estável composta de diversos grupos étnicos, mas especialmente de corpos afro-caribenhos.

\section{Palavras-chave}

Tesauro: Paisagem; grupo étnico; geografia; transporte ferroviário; viagens; Costa Rica. 


\section{Introducción}

El llamado "jungle train" o el ferrocarril al Caribe costarricense -región conocida tradicionalmente como el "Atlántico"- fue una ansiada y accidentada empresa en la historia del país. El ferrocarril fue construido por la necesidad de procurar una conexión con el espacio atlántico y con el fin de sacar al mercado internacional diferentes mercancías -especialmente la producción cafetalera- y de proveer al interior del país de bienes de importación. Esto fue un proyecto nacional de las élites liberales costarricenses de los años 1870 .

El plan pretendía ser una referencia nacional para propiciar un contacto de poblados aislados, alejados y territorios emergentes con el objetivo de forjar la pertenencia a una comunidad nacional y, a la vez, extender - al menos de manera simbólica - la soberanía y los límites territoriales efectivos del Estado costarricense. Sin embargo, lo que se originó efectivamente fue la creación de una identidad regional con fisionomía particular. Peraldo Huertas y Rojas Cedeño indican con respecto a la transformación del paisaje cultural por el ferrocarril: "La dinámica del paisaje cultural a nivel nacional fue muy tenue [sic] aún para los primeros años del siglo XIX. Sin embargo, la inserción de la máquina de vapor, [sic] activó violentamente los aspectos étnicos y culturales, entre otros, y le otorgaron a ese paisaje un [sic] gran versatilidad". 2

De tal forma, hacia finales del siglo XIX, en su primera visita al país, el intelectual salvadoreño Alberto Masferrer (1868-1932) visualiza una región del Caribe donde la "negra sangre de África corre abundante y pura" y una "Tiquicia pura" de "pura raza española, de Galicia", la "verdadera Costa Rica", o sea, esencialmente las ciudades del Valle central -a veces llamado Meseta Central-: Heredia, Cartago y San José. ${ }^{3}$ Entonces, el ferrocarril era el hilo conductor entre dos regiones ubicadas dentro de las mismas fronteras geográficas oficiales, pero que formaban parte de lo que ha llamado de manera muy acertada el latinoamericanista finlandés Jussi Pakkasvirta una "nación esquizofrénica" y "fragmentada". 4

\footnotetext{
${ }^{1}$ Este nombre es utilizado por algunos autores como: Vicky Ellyot "Costa Rica's Jungle Train", The New York Times, [section 10], 28 de julio de 1985, 20, https://www.nytimes.com/1985/07/28/travel/costa-rica-sjungle-train.html (10 de noviembre de 2020).

${ }^{2}$ Gerardo Peraldo Huertas y Ernesto Rojas Cedeño, "La deslizable historia del ferrocarril al Caribe de Costa Rica", Anuario de Estudios Centroamericanos 24, 1-2 (1998): 103, https://revistas.ucr.ac.cr/index. php/anuario/article/view/1828 (10 de noviembre de 2020).

${ }^{3}$ Iván Molina Jiménez, "Limón blues: Una novela de Anacristina Rossi”, en Représentations des Noir(e) $s$ dans les pratiques discursives et culturelles en Caraïbe, ed. V. Lavou Zoungbo (Perpignan: Travaux du GRENAL et collaborations, Centre de Recherches Ibériques et Latino-Américaines, Université de Perpignan Via Domitia, 2006), 168. Recordemos que "tico" es el término con que se llaman a sí mismo los costarricenses y como son también conocidos en el exterior. Este viene de la utilización del diminutivo "tico" en el habla costarricense. Por consiguiente, "Tiquicia" es la tierra de los ticos.

${ }^{4}$ J. Pakkasvirta, ¿Un continente, una nación? Intelectuales latinoamericanos, comunidad politica y las revistas culturales en Costa Rica y Perú (1919-1930) (San José, C.R.: Editorial de la Universidad de Costa Rica, 2005), 129-131.
} 
George W. White diferencia dos tipos de entidades espaciales: la nación y el estado. ${ }^{5}$ El espacio nacional tiene su propio territorio y fronteras. ${ }^{6}$ Nancy Hanway apunta que el espacio de la nación o espacio-nación con el territorio que es definido como perteneciente a la nación y el espacio discursivo de lo nacional son construcciones. ${ }^{7}$ Recordemos la ya tradicional interpretación de B. Anderson con respecto a la nación como "comunidad imaginada". En tal, perspectiva nuestra finalidad es visualizar cómo se dibuja el paisaje caribeño y su confrontación con un paisaje considerado como "costarricense", o bien, "nacional".

Para nuestro análisis hemos recurrido a los relatos de viajeros extranjeros de varias nacionalidades -especialmente estadounidenses- que visitaron el país entre finales del siglo XIX y 1930 y que fueron publicados como obras o bien como artículos en periódicos y revistas del período. Algunas investigaciones -bastante recientes e innovadoras (2018) - ya se han encauzado en el estudio de los viajes, las experiencias y los paisajes en las rutas de Puntarenas-San José y entre Limón-San José tomando en cuenta los relatos de foráneos. ${ }^{8}$ Sin embargo, contamos con un primer trabajo de 2012 sobre los viajes de forasteros, la ruta férrea entre San José y Limón y el aspecto étnico de los relatos. ${ }^{9}$

El antropólogo indio Arjun Appadurai -interesado especialmente en el significado de la globalización- evoca cinco planos o dimensiones de flujos culturales globales: el paisaje étnico, el paisaje mediático, el paisaje tecnológico, el paisaje financiero y el paisaje ideológico. El autor considera que la palabra "paisaje" -en inglés scape- hace alusión a la forma irregular y fluida de estas cinco dimensiones y que dichos "términos intentan hacer notar que no se trata de relaciones construidas objetivamente, que se mantienen fijas con independencia del ángulo desde donde se las miren [...] intenta llamar la atención sobre el hecho de ser, fundamentalmente, constructos resultado de una perspectiva". ${ }^{10}$

\footnotetext{
${ }^{5}$ George W. White, Nation, State and Territory. Origins, Evolutions, and Relationships, Vol. 1 (LanhamBoulder-New York-Toronto-Plymouth, UK: Rownan \& Littlefield Publishers, Inc., 2007).

${ }^{6}$ Joël Bonnemaison y Luc Cambrezy (dir.), La Nation et le territoire, le territoire, lien ou frontière? Tome 2 (Paris: L'Harmattan, 1999), 9.

${ }^{7}$ Nancy Hanway, Embodying Argentine. Body. Space and Nation in $19^{\text {th }}$ Century Narrative (Jefferson, Norh Carolina and London: Mc Farland \& Company, Inc. Publishers, 2003), 6.

${ }^{8}$ Luis Durán Segura, "Viaje, experiencia y paisaje. La ruta Puntarenas-San José en los relatos de extranjeros (Costa Rica, 1840-1880)", On the w@terfront [RCUB] 60, no. 11 (2018): 3-38, https://revistes.ub.edu/ index.php/waterfront/article/view/22295/23734 (23 de noviembre de 2020); Luis Armando Durán Segura, "Viaje, experiencia y paisaje. La ruta Limón-San José en los relatos de extranjeros (Costa Rica, 1880-1940)", Ería. Revista Cuatrimestral de Geografia XXXVIII, no. 2 (2018): 345-365, https://www. unioviedo.es/reunido/index.php/RCG/article/view/12622 (23 de noviembre de 2020). Este último estudio se divide en varios ejes bastante sugerentes: "desde las historias" (pasados, obras, anuncios); "desde los movimientos" (cinestesias, panoramas, agitaciones); "desde los cuerpos" (sensaciones y comodidades) y, "desde los encuentros" (enclaves, choques, comerciantes).

${ }^{9}$ Ronald Soto-Quirós, "De Limón à San José: un voyage vers l'espace de la nation costaricienne", en $L a$ mer Caraïbe, espace de migrations, ed. Michèle Dalmace (Bordeaux: Presses Universitaires de Bordeaux (PUB), Collection de la Maison des Pays Ibériques, Séries Amériques/AMERIBER (CARHISP), 2012), 233-260. Este artículo es una versión muy preliminar de la presente investigación.

${ }^{10}$ Arjun Appadurai, La modernidad desbordada. Dimensiones culturales de la globalización (Montevideo, Uruguay/Buenos Aires, Arg.: Ediciones Trilce S.A./Fondo de Cultura Económica de Argentina, S.A., 2001
} 
Para el autor, estos paisajes vienen a "ser algo así como los bloques elementales (de los juegos de armar infantiles) con los que se construyen lo que a mí me gustaría denominar (extendiendo la idea de Benedict Anderson) los mundos imaginados, es decir, los múltiples mundos que son producto de la imaginación históricamente situada de personas y grupos dispersos por todo el globo". ${ }^{11}$ Ahora bien, Appadurai enuncia específicamente "paisaje étnico" o "etnopaisaje" (ethnoscape) en el contexto de la globalización como "el paisaje de personas que constituyen el cambiante mundo en que vivimos: los turistas, los inmigrantes, los refugiados, los exiliados, los trabajadores invitados, así como otros grupos e individuos en movimiento que hoy constituyen una cualidad esencial del mundo". El antropólogo precisa inmediatamente después que no quiere decir que "ya no existan comunidades relativamente estables o relaciones estables de parentesco, de amistad, laborales o de recreación, lo mismo que de nacimiento, de residencia y otras formas de filiación". ${ }^{12}$

Sin embargo, en términos generales, Appadurai concibe el "paisaje étnico" como aquel "paisaje de identidades de grupo". ${ }^{13}$ Cuillerai y Abélès, con base en el trabajo de Appadurai, explican que:

Los individuos y los grupos producen sus propios paisajes, los paisajes étnicos, en vista de sus propios orígenes y los avatares a los que se someten. [...] En el contexto de la globalización, el concepto de paisaje étnico permite precisamente dar cuenta de la producción de una identidad de grupo, basada en ciertas imágenes, en un paisaje compartido. [...] A diferencia de una visión estática de las representaciones colectivas, el concepto de paisaje étnico tiene por objeto ofrecer una perspectiva dinámica de las identidades que se reelaboran constantemente. ${ }^{14}$

Los mismos autores entienden también que la noción de paisaje es en sí misma ambigua: "Connota tanto el exterior, el mundo como se nos aparece, pero también la interioridad, la representación que llevamos dentro". ${ }^{15}$ Aquí interesa esa noción de "paisaje de identidades" y, más aún, apreciar ese aspecto imaginado desde fuera del flujo de individuos e identidades. Como lo hemos evocado el paisaje se entiende usualmente como un constructo social del espacio -generado por las interacciones sociales y el espacio-, ${ }^{16}$ pero a la vez el territorio y sus identidades se experimentan y se representan y, entonces, se "forja paisaje" según las miradas de los que lo viven y lo observan. De esta manera, se crean retablos de paisajes étnicos y paisajes estrictamente racializados. O sea, existe una operación que lleva a una

\footnotetext{
[primera ed. en inglés 1996]), 47.

${ }^{11}$ Appadurai, La modernidad, 47.

${ }^{12}$ Arjun Appadurai, La modernidad, 47.

${ }^{13}$ Appadurai, La modernidad desbordada. 63.

${ }^{14}$ Trad. nuestra. De ahora en adelante, así consignamos nuestro propio ejercicio de traducción. Marie Cuillerai y Marc Abélès, "Mondialisation: du géo-culturel au bio-politique", Anthropologie et Sociétés 26, 1 (2002): 17-18, https://www.erudit.org/fr/revues/as/2002-v26-n1-as472/000700ar.pdf (28 noviembre de 2020).

${ }^{15}$ Cuillerai y Abélès, "Mondialisation", 17.

${ }^{16}$ Joan Nogué (ed.), La construcción social del paisaje (Madrid: Biblioteca Nueva, 2007).
} 
construcción de espacios con cuerpos vinculada a una estrategia de racialización: un proceso de producción representacional y de categorización que otorga y resalta rasgos somáticos, biológicos o fenotípicos.

Como lo interpreta Banton, a partir de los enunciados R. Miles, la racialización es: "un proceso dialéctico por el cual se atribuye un significado a características biológicas particulares de los seres humanos, como resultado del cual los individuos pueden ser asignados a una categoría general de personas que se reproduce biológicamente". ${ }^{17}$ Sobre el concepto, Buraschi y Aguilar Idañez recuerdan igualmente: "la racialización es el proceso a través del cual se construyen las líneas que demarcan el espacio del racismo, es decir, la producción social de los grupos humanos en términos raciales". ${ }^{18}$ Interesa aquí mostrar la narrativa de cuerpos estigmatizados y racializados en el mundo de las llanuras caribeñas de Costa Rica. ${ }^{19}$

La presente propuesta enfatiza en la visión étnico-racial generada por textos extranjeros, especialmente relatos de viaje sobre Costa Rica y destaca la importancia del estudio de la narración del desplazamiento ferroviario en la construcción de paisajes étnicos y fronteras identitarias. Como lo muestra Marc Desportes, cada nuevo modo de transporte impone nuevas formas de hacer, sentir, ver y de ubicarse, cada uno aporta un enfoque original al espacio que conforma un paisaje. Así, en el siglo XIX, el ferrocarril obligó al viajero a mirar de una nueva manera. ${ }^{20}$ En esta tarea de análisis de relatos de viajes, las fuentes empleadas vienen de bibliotecas y repositorios digitales de diferentes países. ${ }^{21}$

\footnotetext{
${ }^{17}$ Michael Banton, Racial Theories. Second edition (New York: Cambridge University Press, 1998), 184.

${ }^{18}$ Daniel Buraschi y María José Aguilar Idáñez, Racismo y antirracismo. Comprender para transformar (Ciudad Real: Ediciones de la Universidad de Castilla-La Mancha, 2019), 33.

${ }^{19} \mathrm{Al}$ respecto del estudio de los cuerpos humanos a través del prisma de la biología, de la medicina y de las ciencias sociales humanes y sociales, véase, por ejemplo: Gilles Boëtsch, Christian Hervé y Jacques J. Rozenberg (eds.), Corps normalisé, corps stigmatisé, corps racialisé (Bruxelles: De Boeck Supérieur, 2007).

${ }^{20}$ M. Desportes, Paysages en mouvement: transports et perception de l'espace, XVIIIe-XXe siècle (Paris: Gallimard (Collection Bibliothèques des Histoires, Série illustrée), 2005).

${ }^{21}$ Durante más de 25 años, el autor se ha dedicado a recopilar todo tipo material (artículos en periódicos, revistas y libros de viaje) relacionado con los viajeros en Costa Rica. El punto de partida de esta revisión de fuentes fueron algunos trabajos pioneros en Costa Rica que mencionan documentos escritos por extranjeros en Costa Rica: la bibliografía del suizo Pablo (Paul) Biolley (1902) y el índice bibliográfico sobre geografía y geología del costarricense Luis Dobles Segreda (1928), por ejemplo. Véanse: Pablo Biolley, "Bibliografía. Obras publicadas en el extranjero acerca de la República de Costa Rica durante el siglo XIX. Notas compiladas y ordenadas por Pablo Biolley", Revista de Costa Rica en el siglo XIX. Tomo Primero (San José, C.R.: Tipografía Nacional, 1902), 363-404 y Luis Dobles Segreda, Indice bibliográfico de Costa Rica. Tomo Segundo (San José, C.R.: Imprenta Lehmann (Sauter \& Co), 1928. Luego de esa primera identificación se procedió a la búsqueda de manera libre en bibliotecas y a través de internet de material no solamente de Costa Rica sino de toda Centroamérica. Más tarde, el material se consultó personalmente en bibliotecas de Costa Rica y de otros países (Francia, España, Inglaterra y Estados Unidos). Algunos de las obras fueron inicialmente fotocopiadas, fotografiadas o transcritas, otros de los libros y revistas fueron adquiridos y forman parte de la colección personal del autor y, finalmente, algunos documentos fueron recuperados más tarde a partir de repositorios digitales. También, hemos recurrido a algunas compilaciones más recientes que incluyen traducciones de fragmentos de relatos de viajeros en Costa Rica. En lo referente a la bibliografía secundaria, esta se ubicó a través de una búsqueda libre en bibliotecas y centros de documentación y en portales internet. De igual manera, muchas de las obras mencionadas como fuentes
} 


\section{Viajeros, ferrocarril, enclave e impronta afrocaribeña: "la gente de color domina"}

En la construcción del ferrocarril al "Atlántico" a pesar de los intentos de traer fuerza laboral de variados orígenes y nacionalidades para llevar a cabo la tarea, se impuso la mano de obra afrocaribeña o afroantillana -principalmente venida de Jamaica $^{22}$-. En 1872 se contabiliza la llegada de 500 afrocaribeños, en 18731.117 y en 1874 unos $1.152 .{ }^{23}$ A partir de 1873 se da una intensificación de la llegada de jamaicanos y esta inmigración de las islas caribeñas fue fomentada especialmente por el neoyorkino Minor Cooper Keith (1848-1929) a partir de $1879 .{ }^{24}$ Por ese año, Keith comenzó la exportación de los primeros racimos de bananos costarricenses con el fin de rentabilizar con un producto local cerca de la línea ya construida; en 1899 acercó su empresa bananera (la Tropical Trading and Transport Company) a la Boston Fruit Company y así surgió la United Fruit Company; y en 1901 organizó el nuevo ferrocarril, la Northern Railway y en 1905 la Northern absorvió a la Costa Rica Railway monopolizando el sistema de transporte bananero. En este conjunto de empresas, los trabajadores afrocaribeños fueron la fuente principal de mano de obra.

Se calculan en más de 450.000 los afrodescendientes que viajaron de las Antillas a Mesoamérica, y especialmente a Panamá y Costa Rica entre 1850 y $1950 .{ }^{25}$ Dos polos de atracción básicos en el istmo de América Central lo fueron el intento francés de construcción canalera y el proyecto ejecutado en manos norteamericanas. Las estadísticas que existen sobre la migración afrocaribeña a Costa Rica no son siempre fiables y muchas veces no se toman en cuenta las inmigraciones no oficiales. ${ }^{26}$ Según Philippe Bourgois, Keith importó a 10.000 negros de Jamaica entre 1881 y $1891 .^{27}$ Basado en los criterios de Elizabeth McLean Petras, Ronald Harpelle considera que 43.438 jamaicanos fueron a Costa Rica para trabajar en las plantaciones bananeras entre 1891 y 1911. ${ }^{28}$ Según los datos que Aviva Chomsky retoma de M. J. Proudfoot, el total de migración de Jamaica a Costa Rica entre 1900 y 1931 puede contabilizarse en 23.443 individuos. ${ }^{29}$ Lara Putnam postula que la inmigración de afrocaribeños a Limón

\footnotetext{
secundarias han podido ser adquiridas por el autor, consultadas personalmente en bibliotecas o recuperadas de portales digitales. Los fragmentos en español de obras en idioma inglés fueron traducidos por el autor o son recuperados de traducciones ya existentes, pero siempre cotejando con el documento original.

${ }^{22}$ Carmen Murillo Chaverri, Identidades de hierro y humo. La construcción del Ferrocarril al Atlántico. 1870-1890 (San José, C.R.: Porvenir, 1995), 75-79.

${ }^{23}$ Elisavinda Echeverri-Gent, "Forgotten Workers: British West Indians and the Early Days of the Banana Industry in Costa Rica and Honduras", Journal of Latin American Studies 24, no. 2 (mayo 1992): 280 y 282.

${ }^{24}$ Murillo Chaverri, Identidades de hierro y humo, 78 y 82.

${ }^{25}$ Sabas H. Whittaker, Africans in the Americas. Our Journey Throughout The World (New York, Lincoln (NE): Shangai, iUniverse, Inc., 2003), 271; Ronald Harpelle, The West Indians of Costa Rica, Race, Class, and the Integration of an Ethnic Minority (Kingston/Montreal/London/Ithaca: Ian Randle Publishers, McGill-Queen's University Press, 2001), 14, 193-194.

${ }^{26}$ Harpelle, The West Indians, 13.

${ }^{27}$ Philippe Bourgois, Banano, etnia y lucha social en Centro América (San José, C.R.: DEI, 1994), 90.

${ }^{28}$ Harpelle, The West Indians, 17 y 194.

${ }^{29}$ Aviva Chomsky, West Indian Workers and the United Fruit Company in Costa Rica, 1870-1940 (Baton
} 
alcanza su máxima altura cuando el empleo en el canal de Panamá estaba también en su cima, alrededor de 1907 y 1913, y empieza a caer al mismo tiempo que la fuerza laboral del canal era reducida. ${ }^{30}$

El censo de población de Costa Rica de 1864 anota apenas 23 jamaicanos en el país. ${ }^{31}$ Según R. Harpelle, en 1875 Limón era una ciudad de "mil almas" y en 1883, de los 1.273 extranjeros residentes en la región de Puerto Limón, un 68\% eran jamaicanos, o sea, un $48 \%$ de la población total de la provincia. ${ }^{32}$ En efecto, en 1883 se contabilizaban 4.556 extranjeros en Costa Rica, los de Jamaica eran según las provincias del país: 10 en San José, 3 en Heredia, y 886 en el cantón de Limón. Entonces, en total se contabilizan para ese año 902 jamaicanos en el país. ${ }^{33}$ En 1885 , un editorialista estadounidense, E. A. Lever, que había visitado los diferentes países de América Central, cuando se refiere a la "Comarca" o "Zona" de Limón, recuerda que aparte de los norteamericanos que trabajaban para la compañía, había un gran número de habitantes que son "caribes civilizados" y "negros de Jamaica”. ¿Cómo empezó a ser visto Limón y estos grupos en aquella época? Para Lever, Puerto Limón presenta las características propias de un pueblo jamaicano:

Las calles están llenas de mujeres negras desaliñadas, pero de buen humor y perezosos e inmoderados hombres negros, que trabajan solamente cuando son obligados por la verdadera necesidad. Las mujeres, como generalmente es el caso, apoyan tanto a sus esposos como a sus hijos; mientras que éstos forman una pandilla despreciable, retozona y afable de pequeños vagabundos que son desde muy pequeños corrompidos por la atmósfera inmoral que los rodea. ${ }^{34}$

Las cifras de afrocaribeños y jamaicanos -en específico- en Costa Rica varían de autor en autor. En 1888, se estima un total de 839 jamaicanos en el país. ${ }^{35}$ Bonham C. Richardson apunta que, en 1888, por ejemplo, 2.000 jamaicanos habían emigrado a Costa Rica. ${ }^{36}$ En 1892, de un total de 6.289 extranjeros, oficialmente

\footnotetext{
Rouge and London: Louisiana State University Press, 1996), 44-45.

${ }^{30}$ Lara Putnam, The Company They Kept. Migrants and the Politics of Gender in Caribbean Costa Rica, 1870-1960 (Chapel Hill and London: University of North Carolina Press, 2002), 62.

${ }^{31}$ R.C.R, Censo de Población. 1864 (San José, C.R.: Imprenta Nacional, 1868), 67.

${ }^{32}$ Harpelle, The West Indians, 19.

${ }^{33}$ R.C.R. Censo de la República de Costa Rica (1883) (San José, C.R.: República de Costa Rica, Ministerio de Economía, Industria y Comercio, DGEC, 1975), 64-67. Véase también: R.C.R, Secretaria de Salubridad Pública y Protección Social. Departamento de Biodemografía. Aspectos Biodemográficos de la Población de Costa Rica. Informe correspondiente al año 1940. Presentado por el Dr. Pablo Luros (San José, C.R.: Imprenta Nacional, 1942), 31.

${ }^{34}$ Trad. nuestra. [Col.] E. A. Lever, Central America or, The land of the Quiches and Chontales (New Orleans: E. A. Brandao \& Co., Publishers, 1885), 280.

${ }^{35}$ Chester Lloyd Jones, Costa Rica and Civilization in the Caribbean (Madison: University of Wisconsin, 1935), 36.

${ }^{36}$ Bonham C. Richardson, "The Migration Experience", en General History of the Caribbean, Volumen V. The Caribbean in the Twentieth Century, ed. B. Bridget (Paris: UNESCO Publishing; London: MacMillan Caribbean, 2004), 440.
} 
apenas se censan 734 jamaicanos. ${ }^{37}$ En 1896, el francés Alexandre Lambert de SainteCroix -que había llegado a Limón en un navío llamado el Derwent- va a tomar a Limón el buque de carga Fournel que lo llevaría a Cartagena de Indias (Colombia) y de ahí se dirigiría a la Guaira (Venezuela), para luego regresar a su patria. El viajero describe el puerto de Limón de la siguiente manera:

es domingo, los negros y las negras que constituyen la mayor parte de la población, se han vestido con trajes de fiesta, entre más negra es la piel, más claro es el vestido escogido; veo a una negra descalza, con un vestido en muselina blanca muy vaporoso, un corsage escotado con cintas y una cintura verde claro, un sombrero de paja con dos rosas y guantes blancos de hilo, demasiado cortos que dejan ver el brazo negro como de azabache. ${ }^{38}$

Limón va creciendo en población y su particularidad se va acentuando. ${ }^{39} \mathrm{En}$ 1901, la municipalidad de Limón tiene 11.157 habitantes y en $1910,18.195 .{ }^{40}$ En 1904 , de los 5.600 trabajadores de la división de la UFCO en Limón, 4.000 eran jamaicanos. ${ }^{41}$ En 1906, en una obra de Henry Clemens Pearson (1858-1936), un estadounidense nacido en Minnesota que viajó por todo el mundo y se interesó especialmente en las fuentes de caucho en los trópicos, se calculan unos 11.000 negros de Jamaica en las plantaciones cerca de Puerto Limón. ${ }^{42}$ Entonces, los individuos que se establecieron en Costa Rica inicialmente al calor de la construcción del camino de metal para la máquina negra y que, luego, se sumaron a la producción a gran envergadura del banano eran de origen especialmente jamaicano y afrodescendientes como en otras latitudes de América Central. ${ }^{43}$ Los jamaicanos que llegaron a Costa Rica eran esencialmente de origen negro si tomamos en cuenta las estadísticas de población de Jamaica entre 1844 y 1943 donde más del $70 \%$ de la población era de este origen étnico. ${ }^{44}$

\footnotetext{
${ }^{37}$ R.C.R, Aspectos Biodemográficos, 31.

${ }^{38}$ Trad. nuestra. A. Lambert de Sainte-Croix, Onze mois au Mexique et au Centre-Amérique (Paris: Librairie Plon, 1897), 253. En el texto original se utiliza de nuevo el término "négresse". Cursiva nuestra.

${ }^{39}$ Sobre la evolución histórica de la imagen de Limón, véase: Ronald Soto-Quirós, "Desarrollo, étnica y marginalización: imágenes del puerto caribeño de Limón, Costa Rica (1838-1967)”, Études caribéennes 21 (abril 2012), https://journals.openedition.org/etudescaribeennes/5715 (23 de noviembre de 2020). Sobre el establecimiento de Limón, véase: Carmen Hutchinson Miller, The Province and Port of Limon: metaphors for Afro-Costa Rican black identity (Heredia, C.R.: EUNA, 2015), 51-89.

${ }^{40}$ Harpelle, The West Indians, 19.

${ }^{41}$ Bourgois, Banano, etnia, 90.

${ }^{42}$ Henry C. Pearson, What I saw in the Tropics (New York: The India Rubber Publishing, Co., 1906), 186187.

${ }^{43} \mathrm{~A} 1$ respecto de los antillanos británicos en América Central véanse los estudios de L. Putnam: Putnam, The Company y; Lara Putnam, "Foráneos al fin: La saga multigeneracional de los antillanos británicos en América Central, 1870-1940", en La negritud en Centroamérica: entre raza y raíces, ed. L. Gudmundson y J. Wolfe (San José, C.R: EUNED, 2012), 367-403.

${ }^{44}$ G. Eisner, Jamaica. 1830-1930. A study in economic growth (London: Manchester University Press, 1961), 153; James C. Riley, Poverty and Life Expectancy. The Jamaican Paradox (New York: Cambridge University Press, 2005), 24.
} 
En 1900, según el estadounidense -originario de Massachusetts-, Henry Robertson Blaney (1855-1913), Limón formaba parte de los puertos del "círculo del Caribe Dorado". ${ }^{45}$ En ese "Caribe Dorado", la marca del banano era omnipresente. Entre fines del siglo XIX y principios del siglo XX, como indica R. J. Viales Hurtado, el "paisaje de la plantación bananera transformó la región atlántico-caribe de Costa Rica" ${ }^{46}$ H. C. Pearson apunta en 1906 que: "No sólo Costa Rica es llamada de manera justa la República Bananera, sino que Puerto Limón es una ciudad de banano". ${ }^{47}$ En este mismo sentido, el prominente periodista y escritor norteamericano oriundo de Filadelfia (Estados Unidos) y colaborador en varios escritos con Henry Ford y otros industriales americanos, Samuel Crowther (1880-1947), apunta en 1929: "El café gobierna en las tierras altas, pero las reglas del banano en la costa caribe y se centra en Limón donde la United Fruit Company, que es la única empresa grande en el país, tiene su estación principal y ciudad". ${ }^{48}$

Efectivamente, Limón era un enclave. ${ }^{49} \mathrm{Al}$ respecto, los españoles de Valencia Segarra y Juliá indican en 1907: “Aquello, la Línea, es un feudo anglosajón enclavado en territorio latino-americano". ${ }^{50}$ El famoso explorador, hombre político, autor y editor norteamericano -y quien fue esposo de la conocida aviadora norteamericana desaparecida Amelia Mary Earhart "Lady Lindy"-, George Palmer Putnam (1887-1950), en sus observaciones hechas sobre un viaje en 1912, resume la situación de enclave de la ciudad caribeña: "Limón está adueñado, corazón y alma, por la United Fruit Company [...] La compañía posee las tierras y en ellas cultiva su fruta. Posee ferrocarriles en Costa Rica y en otras partes, y en ellos transporta los bananos de la plantación al muelle". ${ }^{51}$ En 1924, el viajero y narrador neoyorkino Harry La Tourette Foster (1894-1932) menciona también esa condición de enclave del puerto caribeño de Costa Rica: "Ese puerto del Atlántico Limón es en sí mismo simplemente un puerto promedio de la costa este - una ciudad con casas de madera desvencijada detrás de un gran muelle de bananos, con una población de negros jamaicanos importados por la Fruit Company que es dueña de esta orilla caribeña". ${ }^{52}$

\footnotetext{
${ }^{45}$ Trad. nuestra. Henry R. Blaney, The Golden Caribbean (Boston: Lee \& Shepard, Publishers, 1900), 48.

${ }^{46}$ Ronny J. Viales Hurtado, "La región Atlántico-Caribe de Costa Rica: las imágenes de la construcción regional", Memorias. Revista digital de Historia y Arqueología desde el Caribe [año] 12, no. 30 (sep.-dic. 2016): 219, http://www.scielo.org.co/pdf/memor/n30/n30a10.pdf (23 de noviembre de 2020).

${ }^{47}$ Trad. nuestra. Pearson, What I saw in the Tropics, 185.

${ }^{48}$ Trad. nuestra. Samuel Crowther, The Romance and Rise of the American Tropics (New York: Doublebay, Doran \& Company, Inc., 1929), 249.

${ }^{49}$ Véase sobre el tema: Ronny J. Viales Hurtado, "La reconceptualización del "enclave" bananero desde la perspectiva de la historia económica. Una propuesta a partir del caso de la región Atlántica (Caribe) costarricense entre 1870 y 1950", en El Caribe centroamericano, ed. J. Pakkasvirta y K. Wilska (Helsinki, Finlandia: Publicaciones del Renvall Institute, 2005), 32-71.

${ }^{50}$ José Segarra y Joaquín Juliá, Excursión por América: Costa Rica (San José, C.R.: Imprenta de Avelino Alsina, 1907), 67. Una transcripción un poco diferente viene en: Durán Segura, "Viaje, experiencia y paisaje. La ruta Limón-San José”, 359.

${ }^{51}$ Trad. nuestra. George Palmer Putnam, The Southland of North America (New York-London: G. P. Putnam's Sons, 1914), 99-100.

${ }^{52}$ Trad. nuestra. Harry L. Foster, A gringo in Mañana Land (London: Joh Lane the Bodley Head Ltd., 1924), 340-341.
} 
Otra ojeada similar es la de un francés que realiza diferentes misiones en América Latina - Guyana francesa, Guatemala y Costa Rica-, Rodolphe Henry Edouard Saillard (1871- ¿?). El galo visita Costa Rica a principios del siglo XX y hace el recorrido de San José, pasando por Cartago y atravesando un camino pintoresco para llegar a la costa del Caribe. En su relato de 1906, el viajero explica

Es de Jamaica y de las Antillas inglesas que vienen todos estos trabajadores negros. Una compañía americana los contrata por dos años, los lleva en sus propios barcos, y los mantiene en las plantaciones de banano; luego, el contrato acabado, son transportados de vuelta a país. En general, estos negros, los más inteligentes $\mathrm{y}$ trabajadores de los que viven en América, logran amasar un pequeño peculio. ${ }^{53}$

El inventor, escritor, editor y hombre político originario de Boston (Estados Unidos) Frederick Upham Adams (1859-1921) señalaba en 1914 que estos afrocaribeños formaban parte de esos "negros" considerados como "trotamundos de su nativa y bella isla de Jamaica, pero que son libres y capaces de venir e ir, y miles de ellos hacen el viaje de regreso a su isla anualmente" ${ }^{54}$ Una revista norteamericana de 1911 apuntaba: "Jamaicanos y otros nativos de las islas de las Antillas encuentran este clima [el de Limón] saludable y agradable; entre dieciséis y dieciocho mil viven en la Línea y en Limón". ${ }^{55}$ El norteamericano nacido en Kansas -especialista en agricultura, explorador y conocido eugenista- Paul Bowman Popenoe (1888-1979) considera en 1922 que se podían calcular unos 18.000 "afrocaribeños británicos de color" en las fincas de banano en la provincia de Limón. ${ }^{56}$

Entonces, en ese mundo caribeño un personaje emblemático era el trabajador afrocaribeño. En 1913, el periodista y escritor norteamericano Frederick Palmer (1873-1958) apuntaba: "Para el banano el hombre es el negro jamaicano. Su imagen con un racimo de bananos en su hombro corriendo para subir la pasarela de un vapor es la inseparable característica del Caribe". ${ }^{57}$ Más tarde, en 1917, los esposos norteamericanos Calvert indican: "la imagen de un negro jamaiquino con un manojo de plátanos en el hombro es la más inseparablemente característica del Caribe"58. Los "cargadores de bananos" están omnipresentes en la iconografía de la época como, por ejemplo, en las tarjetas postales. ${ }^{59}$ La corporalidad afrocaribeña se imponía en ese territorio y era recuperada en los relatos.

\footnotetext{
${ }^{33}$ Trad. nuestra. Rodolphe Saillard, "En traversant Costa Rica", Le Tour du Monde XII [Nouvelle série], no. 45 (nov. 1906): 538. Otra propuesta de traducción de este fragmento aparece en otro artículo: Durán Segura, "Viaje, experiencia y paisaje. La ruta Limón-San José", 361.

54 Traducción nuestra. Frederick Upham Adams, Conquest of the Tropics (Garden, City, New York: Doubleday, Page \& Company, 1914), 193.

${ }_{55}$ Trad. nuestra. “Costa Rica Towns”, The Pan American Magazine XII, no. 1 (mayo 1911): 345.

${ }^{56}$ Trad. nuestra. Paul B. Popenoe, "Costa Rica, Land of the Banana”, The National Geographic Magazine XLI, no. 2 (feb. 1922): 205.

${ }^{57}$ Trad. nuestra. Frederick Palmer, Central America and its problems (New York: Moffat, Yard \& Co., 1913), 220.

${ }^{58}$ Durán Segura, "Viaje, experiencia y paisaje. La ruta de Limón-San José”, 360.

${ }^{59}$ Enrique Camacho Navarro, Cómo se pensó Costa Rica. Imágenes e imaginarios en tarjetas postales: 1900-1930 (México, D.F.: Universidad Nacional Autónoma de México, 2015), 317-344.
} 
Como indica el historiador L. Gudmundson: "En Costa Rica, por ejemplo, el centro de la UFCO fueron los antillanos, los únicos que conocían cómo cultivar al banano". ${ }^{60}$ En 1908, el francés Désiré Pector (1855-1939) -quien fue cónsul de Nicaragua y Honduras en París- explica que para "los trabajos bastante dolorosos de la recolección de banano, se sirven generalmente de la mano de obra negra de Jamaica (1.000 hombres)". ${ }^{61}$ Según G. P. Putnam, en 1914, estos afrocaribeños llegaban al país y se sumaban a estas labores también por la supuesta "incapacidad de los costarricenses de resistir a las privaciones climáticas de las tierras bajas". ${ }^{62}$ La razón de tal presencia en Costa Rica también la observa Arthur J. Ruhl cuando explica que, si "el trabajo manual es hecho por negros importados, es porque ellos son mejores trabajadores en el país caliente que los campesinos nativos -a los costarricenses no les gusta vivir y trabajar en el país de banano". ${ }^{63}$

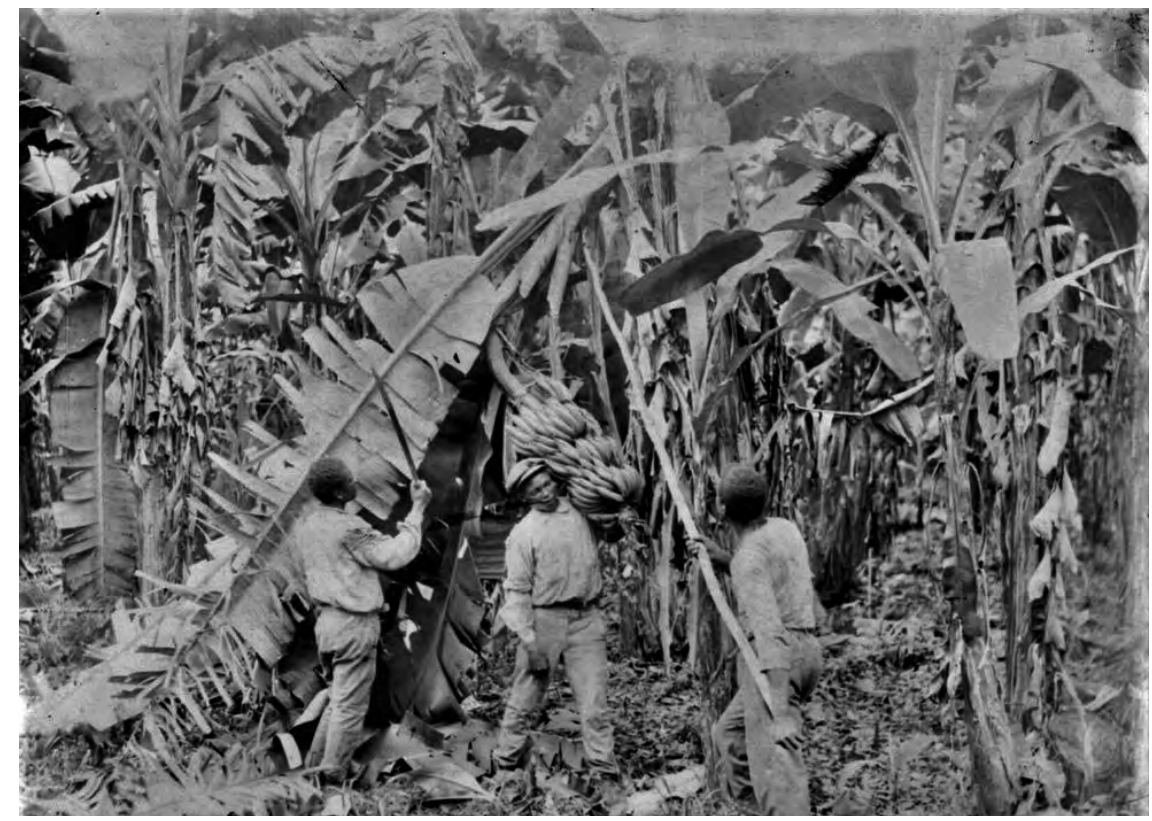

Figura 1. Trabajadores afrocaribeños en finca bananera del Caribe costarricense

Fuente: "Costa Rica workers cutting bananas from tres". Wikimedia Common. Library of Congress. Carpenter Collection. Entre 1910-1920.

\footnotetext{
${ }^{60}$ Lowell Gudmundson, “Prisioneros de enclave o forjadores de una precoz modernidad? Los afroantillanos y el Atlántico en la historia [de] Centroamérica”, en Nuestra herencia caribeña. Del olvido a la memoria 5, ed. R. Cáceres (San José, C.R.: Cátedra de Estudios de África y el Caribe, Universidad de Costa Rica; UNESCO San José, Project supported by The Slave Route; Colegio de Licenciados y Profesores en Letras, Filosofía, Ciencias y Artes, 2011), 85.

${ }^{61}$ Trad. nuestra. Désiré Pector, Les richesses de l'Amérique centrale. Guatemala, Honduras, Salvador, Nicaragua, Costa-Rica. Préface de M. E. Levasseur (Paris: Librairie Orientale \& Américaine E. Guilmoto, Éditeur, s.f. (ca. 1908)), 165.

${ }^{62}$ Putnam, The Southland 114.

${ }^{63}$ Trad. nuestra. Arthur J. Ruhl, The Central Americans (New York-London: Charles Scribner's Sons, 1928), 66.
} 
Igualmente, en 1926, el periodista, viajero, fotógrafo y conferencista norteamericano nativo de Ohio, Frank George Carpenter (1855-1924), bien conocido por sus libros de texto en geografía y una serie llamada Carpenter's World Travels que ayudan a la popularización de la antropología cultural y la geografía, en su obra Lands of the Caribbean, cuando se refiere a las plantaciones bananeras de la United Fruit Company, recuerda particularmente: "La mayoría de los trabajadores en las plantaciones de Costa Rica son negros de Jamaica que parece ser la única raza capaz de trabajar duro en este clima". ${ }^{64}$ Esa condición "física" y "racial" de los cuerpos afrocaribeños los aventajaba en ese espacio. Los periodistas Segarra y Juliá explican en 1907 de manera extensa sobre la predominante presencia de los afrodescendientes y las razones:

La gente de color domina en la zona de Limón por los fueros de una superioridad numérica aplastante. Son negros jamaicanos casi todos, que van allí atraídos por la riqueza que determina la importancia agrícola de la comarca. Y los hay jornaleros para las faenas del campo, y peones de las obras y tráfico de la línea, y empleados en las oficinas de las haciendas, y sastres y mecánicos y regentes de comisariatos ó almacenes de víveres ...

Hay una razón de peso que explica la supremacía numérica del elemento negro en esta zona excesivamente cálida y poco salubre por lo general: lo relativamente bien que esta gente soporta los rigores del clima que la raza blanca no puede soportar [...] Más aún que el predominio numérico de la gente de color sobre la gente blanca, es absoluto el predominio de la lengua inglesa. ${ }^{65}$

Los afrocaribeños con su cultura y su lengua formaban parte de un mundo multicultural que el literato costarricense Manuel Argüello Mora llamó ya en 1893 la "nueva Babilonia". ${ }^{66}$ Limón es cada vez más un espacio cosmopolita. ${ }^{67}$ No hay que olvidar las diferentes nacionalidades y etnias que lo pueblan o, por ejemplo, las famosas "zonas blancas" - los espacios de norteamericanos- en los enclaves de América Central. ${ }^{68}$ El mundo del puerto caribeño, era, evidentemente, un área con un mercado de trabajo segmentado por clase, raza y género. ${ }^{69}$ En 1906, H. C. Pearson

\footnotetext{
${ }^{64}$ Trad. nuestra. Frank G. Carpenter, Lands of the Caribbean (Garden City/New York: Doubleday, Page \& Company, 1926), 61.

${ }^{65}$ Cursivas originales. Segarra y Juliá, Excursión por América: Costa Rica, 64-67. Un parte de este pasaje también es mencionado por: Durán Segura, "Viaje, experiencia y paisaje. La ruta Limón-San José”, 359.

${ }^{66}$ Fernando González Vásquez y Elías Zeledón Cartín, Crónicas y relatos para la historia de Puerto Limón (San José, C.R.: Ministerio de Cultura, Juventud y Deportes, Centro de Investigación y Conservación del Patrimonio Cultural, 1999), 193.

${ }^{67}$ Véase: Sussy Vargas Alvarado, El Caribe limonense a través de la mirada y la obra de Hans Wimmer: 1903-1947 (San José, C.R: Autora, 2018), 45-64.

${ }^{68}$ Ronald Harpelle, “Zonas blancas": Comunidades de enclave norteamericanas en América Central”, en $L a$ negritud en Centroamérica: entre raza y raices, ed. L. Gudmundson y J. Wolfe (San José, C.R: EUNED, 2012), 405-434.

${ }^{69}$ Véase: Ronny J. Viales Hurtado, “La segmentación socio-racial en el capitalismo periférico. Globalización, circulación de personas, transnacionalismo y mercado de trabajo en el "enclave" bananero de Costa Rica, 1899-1930”, en Historia de las desigualdades étnico-raciales en México, Centroamérica y el Caribe (siglos XVIII-XXI), ed. C. Lacaze, R. Soto-Quirós, R. J. Viales Hurtado (San José, C.R.: Universidad de Costa Rica, Vicerrectoría de Investigación: Centro de Investigaciones Históricas de América Central, en colaboración con AMERIBER, Université Bordeaux Montaigne (Bordeaux), 2019), 93-128.
} 
indica que Limón bajo una temperatura de $90^{\circ} \mathrm{F}$ a las 10 a.m, "las calles estaban agolpadas con la mezcla más vivaz de porteros, vendedores de fruta, soldados, negros de Jamaica, chinos, y costarricenses nativos". ${ }^{70}$ En 1912, Lilian Elwyn Elliot (18741963) -una viajera y periodista británica que escribe en revistas norteamericanasobserva sobre la ciudad:

Limón tiene una población permanente de unos doce mil habitantes, a la que se añaden gregariamente los viajeros en tránsito, las visitas de los vapores y una afluencia ocasional de la "Línea" del banano, donde trabajan quince mil jamaicanos. La población de Limón es en gran parte negra, principalmente antillana, con unos pocos cientos de chinos dedicados al comercio, algunos hindúes y sirios, y un poco de muchas otras nacionalidades, como en las ciudades portuarias de cualquier parte del mundo. La inmigración de asiáticos está ahora prohibida por el gobierno de Costa Rica. ${ }^{71}$

En 1911, un artículo de una revista norteamericana propone un retrato similar: "Limón es el hongo producto del ferrocarril y de la industria bananera: hace cuarenta años no existía en absoluto, pero hoy en día es una ciudad ya de cierta nota y siempre en crecimiento". ${ }^{72} \mathrm{El}$ artículo de la revista continúa precisando sobre el tipo de población: "La mayor parte de su población son los negros empleados por los bananeros o en el trabajo constante de los muelles [...] pero también hay costarricenses, italianos, españoles, algunos chinos y japoneses, algunos funcionarios americanos, y siempre algunos visitantes en su camino hacia y desde San José". ${ }^{73}$

Era una ciudad y región con gran mayoría afroantillana, pero también de una gran heterogeneidad. ${ }^{74}$ Esa situación generaba preocupación entre los nacionales de un país que se imaginaba y había sido imaginado por extranjeros desde la primera mitad del siglo XIX como un territorio de blancos. ${ }^{75}$ La intranquilidad con respecto a la presencia afrocaribeña provocó manifestaciones de racismo antinegro durante las primeras tres décadas del siglo XX. ${ }^{76}$ Algunos recuerdan en esos años que "Limón es un pedazo de Costa Rica", no solamente "una caterva de antillanos que únicamente cargan bananos" y consideraban que la región no debía ser vista como "la Cayena de Costa Rica [...] la Penitenciaria de la República [...] el Nuevo mundo poblado por los galeotes de la Conquista". ${ }^{77}$

\footnotetext{
${ }^{70}$ Trad. nuestra. Pearson, What I saw in the Tropics, 186.

${ }^{71}$ Trad. nuestra. L. E. Elliot, "Towns of Costa Rica”, The Pan American Magazine XIV, no. 2 (junio 1912): 23.

72 “Costa Rica Towns", 345.

73 “Costa Rica Towns", 345.

${ }^{74}$ Lara Putnam, "Contact Zones: Heterogeneity and Boundaries in Caribbean Central America at the Start of the Twentieth Century", Iberoamericana. América Latina-España-Portugal 6, no. 23 (2006): 113-126.

${ }^{75}$ Ronald Soto-Quirós, "Imaginando una nación de raza blanca en Costa Rica: 1821-1914", Amérique Latine : Histoire et Mémoire. Les cahiers ALHIM 15 (2008): 233-271.

${ }^{76}$ Ronald Soto-Quirós, ““YY si el olor y el color de...”: racismo en la Costa Rica de principios del siglo XX”, Aguaita. Revista del Observatorio del Caribe Colombiano 17-18 (diciembre 2007/junio 2008): 41-58.

${ }^{77}$ Doctor Sisawath, “Crónicas porteñas. Desde Limón”, La Prensa Libre, 19 de junio de 1914, 4.
} 
Sin embargo, era evidente que la llegada de afrocaribeños impuso un cambio en los patrones de población nacional. No se trata de una "invasión" como algunos habían querido mostrarlo, pero eran un cambio que provocaba inquietud entre algunos y José Guerrero, el oficial encargado del departamento de estadística desde 1924 y coordinador del censo nacional, anunciaba en su informe del censo que eran "dos razas primordialmente las que pueblan a Costa Rica; la blanca y la negra" y escribía en 1930 un artículo titulado: “CCómo se quiere que sea Costa Rica, blanca negra?”.78 En el informe de febrero de 1928 del único censo realizado en Costa Rica a principios del siglo XX y antes de 1950, el costarricense José Guerrero anuncia una población total en Costa Rica de 471.524. De esta población se estiman 44.340 extranjeros (un $9,40 \%$ ) y de éstos, un 38,9\% eran jamaicanos, o sea, unos 17.248. Se trataba de la población de extranjeros más importante seguida por los nicaragüenses. En cuanto a la población nacional catalogada como negra se suman 19.136 (un 4,1\%) y 2.123 mulatos. Del total de población extranjera (44.340), 18.529 (un 41,8 \%) eran considerados como negros. ${ }^{79}$

En el caso particular de Limón, de un total de 32.278 residentes, se calcula un $57 \%$ de ascendencia africana (incluidos mulatos): 18.003 negros y 419 mulatos. ${ }^{80}$ En una muestra realizada del Censo de 1927 se estima en Limón, según el país de origen sobre la base del lugar de nacimiento, un 28,2 \% era de Jamaica y un 5,3\% del resto del Caribe y se establece según el "color o raza", un 54,3\% de negros y un 2,1 $\%$ de mulatos. ${ }^{81}$ En Limón, según Lara Putnam apunta, con base en dicho Censo de 1927 , un $55 \%$ de los residentes hablaba inglés como lengua materna; tres quintos de los hablantes de inglés habían nacido en el extranjero; un $86 \%$ de éstos en Jamaica; un $96 \%$ de los negros hablaba inglés y; un $95 \%$ por ciento de los hablantes de inglés eran negros. ${ }^{82}$

Esta especificidad de Limón en términos étnico-culturales es recuperada por un folleto de promoción turística en idioma inglés de la oficina de turismo de Costa Rica. Dicho documento publicado en 1935 aclara sobre la calidad extranjera de sus pobladores y el porqué de su presencia en el país: "La población de Limón está compuesta principales por negros, antillanos traídos para trabajar en las tierras bananeras, cuyo clima cálido y húmedo no gusta al nativo costarricense, que por naturaleza es amante de las hermosas y frescas tierras altas". ${ }^{83}$ En las diferentes

\footnotetext{
${ }^{78}$ Véase sobre Guerrero en: Ronald Soto-Quirós, "Un otro significante en la identidad nacional costarricense: el caso del inmigrante afrocaribeño, 1872-1926”, Boletín AFEHC 25 (octubre 2006): 20, https://www. afehc-historia-centroamericana.org/_articles/portada_afehc_articulos31.pdf (29 de noviembre de 2020)

${ }^{79}$ R.C.R., Censo de población de Costa Rica. 11 de mayo de 1927 (San José, C.R.: Ministerio de Economía y Hacienda, Dirección General de Estadística y Censos, 1960), 41, 90, 93. Luros y Jones contabilizan 17.245: R.C.R, Aspectos Biodemográficos de la Población, 31; Chester Lloyd Jones, Costa Rica and Civilization, 36.

${ }^{80}$ R.C.R., Censo ... 1927, 90.

${ }^{81}$ Ronny J. Viales Hurtado, Después del enclave. Un estudio de la Región Atlántica Costarricense (San José, C.R.: Editorial de la Universidad de Costa Rica, 1998), 49-51.

${ }^{82}$ Putnam, The Company They Kept, 65.

${ }^{83}$ Trad. nuestra. Obra sin paginar. Véase la introducción (folio 2 verso): R.C.R., Costa Rica. "The Heart
} 
versiones de otro folleto turístico nacional de la década de 1930 y cuyo título es Sight Seeing in Costa Rica se vuelve a percibir la misma insistencia sobre la singularidad de la población limonense, pero en esta ocasión de manera aún más explícita:

La mayoría de la población de Puerto Limón es de color, pero el visitante debe tener en cuenta que los negros no son realmente costarricenses. Son antillanos británicos traídos de Jamaica para trabajar en las plantaciones de banano y cacao que se extienden a lo largo de las regiones costeras y que dan a Limón ese toque pintoresco que permite comparar el lugar con una ciudad [1934] [con muchas ciudades [1935 y 1936] en las Antillas Británicas. ${ }^{84}$

Como si fuera algo imprescindible por destacar para salvaguardar la reputación de los costarricenses y su supuesta condición étnico-racial, en 1946, el folleto de propaganda turística volvía a emplear la misma frase -con algunas pequeñas variaciones- con respecto a los habitantes de Limón. ${ }^{85}$ Ese "pintoresco" Limón del enclave bananero, era tierra de extranjeros y estos extranjeros configuran un paisaje racializado muy diferente al imaginado para el conjunto de lo que se interpretaba como Costa Rica y cuyo ejemplo esencial era el Valle Central. Recordemos de nuevo que los viajeros por más de un siglo, pero en especial los norteamericanos durante las primeras décadas del siglo XIX transmitían la imagen de una Costa Rica "blanca" ${ }^{86}$ Los relatos de viaje y el recuento sobre el trayecto del ferrocarril permitirán esbozar una "otredad". Desde los primeros pasos de la salida de Limón el ambiente es más un mundo habitado por cuerpos diferentes.

\section{Viajeros, recorrido ferroviario, cuerpos afrodescendientes y fronteras identitarias: "el cinturón negro y el cinturón de bananos"}

El recorrido entre Limón y San José o viceversa -unos 160 kilómetrosrepresentaba atravesar las llanuras costeras del Caribe y, luego, un ascenso hacia el Valle Central donde se encuentra la capital. Puerto Limón está a 3 metros sobre el nivel del mar y San José a unos 1.300 m.s.n.m. Antes de llegar a la capital, el tren atravesaba pueblos o ciudades como Turrialba cuya altitud es de entre 638 y 646 m.s.n.m (a unos 64 km. de la San José) y Cartago -la antigua capital colonial- a unos

of The Americas". The Tourist's Paradise. $2^{\text {nd }}$. Ed (San José, C.R.: National Tourist Board of Costa Rica, 1935).

${ }^{84}$ Trad. nuestra. R.C.R. Sight Seeing in Costa Rica. The Heart of the Americas. A Booklet of Useful Information (San José, C.R.: National Tourist Board of Costa Rica, ca. 1934), 7-8; R.C.R., Sight Seeing in Costa Rica. The Heart of the Americas. A Booklet of Useful Information. $3^{\text {rd }}$. Ed. (San José, C.R.: National Tourist Board of Costa Rica, 1935), 5; R.C.R., Sight Seeing in Costa Rica. The Heart of The Americas. A Booklet of Useful information. $4^{\text {th }}$ ed. (revised) (San José, C.R: National Tourist Board of Costa Rica, C.R.: Imprenta Borrasé, 1936), 5.

${ }^{85}$ Trad. nuestra. R.C.R., Sight Seeing in Costa Rica. The Heart of The Americas. A Booklet of Useful Information (San José, C.R.: National Tourist Board of Costa Rica, 1946), 11-12.

${ }^{86}$ Ronald Soto-Quirós, ““"Whiteness studies” y relatos de viajeros: los costarricenses en las miradas anglosajonas (1844-1868)", Boletín AFEHC 57 (abril/junio 2013), http://www.afehchistoriacentroamericana. org/index.php?action=fi_aff\&id=3592) (Sitio innaccesible. Revista fuera de servicio). 
1435 ms.n.m y a unos 24 km. al sureste de San José. Las escenas entre Limón a San José fueron siempre alabadas por los viajeros por su belleza natural y exotismo. ${ }^{87} \mathrm{El}$ inventor, escritor, editor y hombre político originario de Boston (Estados Unidos), Frederick Upham Adams (1859-1921), resalta en su obra que el "paseo de Puerto Limón a San José es uno de los más bellos del mundo". ${ }^{88}$ El ambiente era comparado con los paisajes de Ceylán (hoy Sri Lanka). Así, en 1909, M. de Périgny explica igualmente que: "La línea del ferrocarril que une Puerto Limón con San José tiene 166 kilómetros de largo y el trayecto se hace en seis horas. Es uno de los recorridos más hermosos que se puedan hacer, comparable al del ferrocarril de Ceylán" ${ }^{89}$

Un folleto de la Pan American Union sobre Costa Rica explica sobre el ferrocarril al "Atlántico": "La línea principal sale de Puerto Limón, pasando por Matina, Siquirres, Turrialba y Cartago, hasta llegar a San José, la capital, a una distancia de 103 millas (166 kilómetros)". ${ }^{90}$ En 1911, William W. Rasor escribía en una publicación norteamericana: "Es uno de los paseos más bellos que se puedan imaginar, desde la costa hasta la meseta montañosa; toda variedad de paisajes tropicales da paso a las murallas de piedra, arrastradas por rosas y moras, de Cartago y a través de las encantadoras plantaciones de café perfumado hasta el soleado lugar donde se encuentra San José a los pies de dos cadenas montañosas". ${ }^{91}$

El cambio de ambientes que se va percibiendo en la ruta es manifiesto por muchos extranjeros. A. J. Ruhl escribe en sus escritos que se trata de "tomar la hermosa subida del ferrocarril desde el "país cálido" a la capital". ${ }^{92}$ En el sentido de San José a Limón, G. P. Putnam en 1914 narraba que "primero el tren sube de San José a Cartago, la antigua capital". Luego el relato señala que tras "pasar algunas millas por las aristocráticas e inmaculadas fincas de café, el cultivo del país se vuelve cada vez menos sensible y su estado salvaje desigual de modo repentino es cada vez más aparente." El viajero se ve luego sumergido entre las "bellas vistas del despeinado paisaje, con colinas y valles, desfiladeros de ríos, bosques”. Finalmente, según añade Putnam, aparecen "las profundidades del bosque, pantanos y la tierra del Banano". 93

Las horas, distancias y estaciones del trayecto forman parte también de las impresiones de los viajeros. Un folleto turístico oficial costarricense en idioma inglés de 1936 aporta el siguiente itinerario entre Limón y San José: la salida de Limón se hace diariamente a las 10:30 a.m. y la llegada a San José a las 4:45 p.m. La distancia

\footnotetext{
${ }^{87}$ Durán Segura, "Viaje, experiencia y paisaje. La ruta Limón-San José”, 352-354.

${ }^{88}$ Trad. nuestra. Adams, Conquest of the Tropics, 169.

${ }^{89}$ Versión de: Miguel Ángel Quesada Pachecho, Entre silladas y rejoyas. Viajeros por Costa Rica de 1850 a 1950 (Cartago, C.R.: Editorial Tecnológica de Costa Rica, 2001), 577. En el original: Périgny, Les cinq républiques, 44.

${ }^{90}$ Trad. nuestra. The Pan American Union, Costa Rica. General Descriptive Data (Washington, D.C.: Government Printing Office, 1924), 22.

${ }_{91}^{91}$ Trad. Nuestra. W. W. Rasor, "Railroads in Costa Rica”, The Pan-American Magazine XII, 1 (mayo 1911): 386-388.

92 Trad. nuestra. Arthur J. Ruhl, “Campaignig in Costa Rica”, The Outlook (enero 1914): 35.

${ }_{93}$ Trad. nuestra. Putnam, The Southland, 89-91.
} 
entre Limón y San José es de 103,2 millas (166,08 kilómetros). Se mencionan diecisiete estaciones. Algunos puntos importantes del camino son: Siquirres a 37,1 millas de Limón (a 66,1 de San José) donde se hace el almuerzo y a 60 metros de altitud; Peralta a 55,2 millas de Limón (48 de San José) y a 322 metros de altitud; Turrialba a 63,4 millas de Limón (39,8 de San José) y a 621 metros de altitud; Cartago a 90,4 millas de San José (12,8 de San José) y San José a 1.158 metros de altitud. ${ }^{94}$

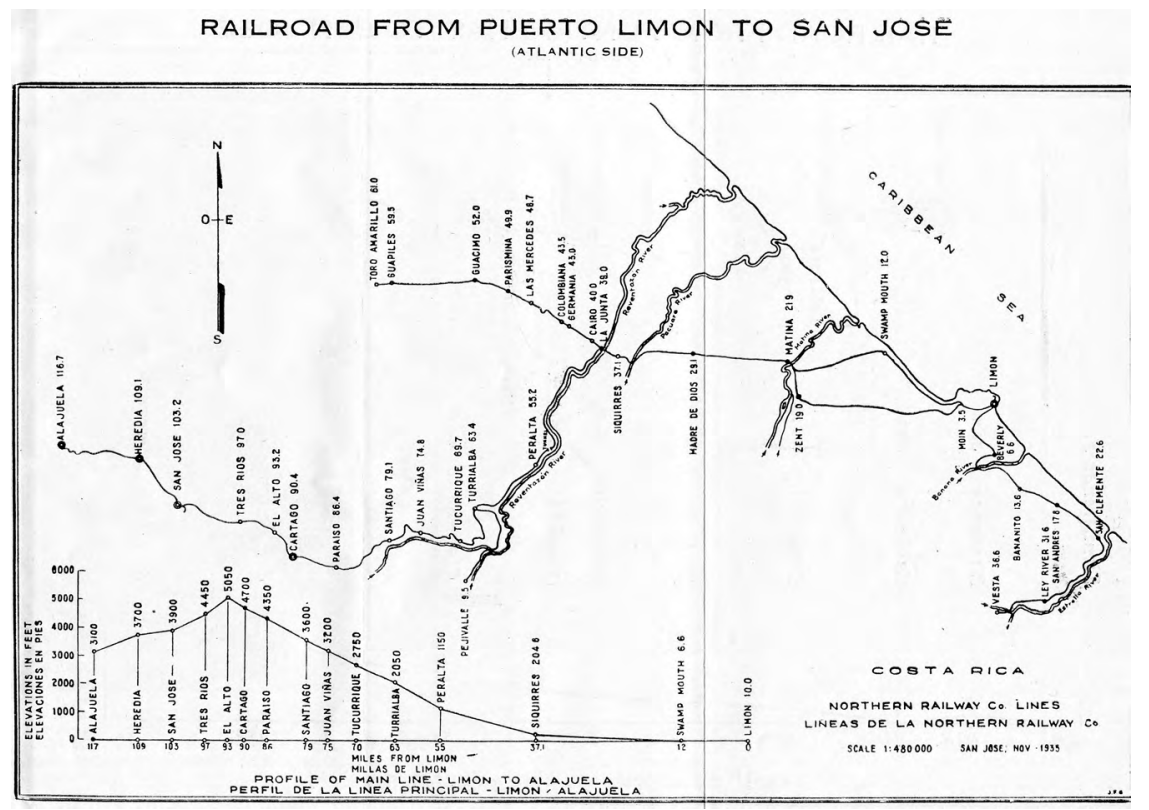

Figura 2. Mapa de la ruta entre Limón y San José

Fuente: R.C.R, Sight Seeing [1936]. Anexos.

Ese recorrido de Limón a San José empezaba con la descripción por los viajeros de un de un paisaje con una tonalidad particular. Las impresiones de los viajeros sobre esos primeros kilómetros del ferrocarril plasman bien las características propias de una región bananera conformada por un conjunto de cuerpos de tez oscura. Los pasajeros extranjeros en el interior del medio de transporte podían cruzar muy seguido a los afrocaribeños. El encuentro podría generar aversión entre éstos. Como indica Durán Segura, los extranjeros emplearon "la vista, el oído y el olfato para realizar una lectura racial" en esos encuentros o choques. ${ }^{95}$ En ese sentido, viniendo de San José, en la estación de Juan Viñas, el sacerdote alemán Bernard August Thiel (1850-1901), segundo obispo de Costa Rica de 1880 a 1901, explica el ambiente cuanto más nos vamos acercando a las llanuras del Caribe:

\footnotetext{
${ }^{94}$ R.C.R., Sight Seeing in Costa Rica [1936], 7. Véase un mapa de la ruta ferroviaria en 1903: Rodrigo Quesada Monge, "Ferrocarriles y crecimiento económico: el caso de la Costa Rica Railway Company, 1871-1905”, Anuario de Estudios Centroamericanos 9, 1 (1983): 94.

${ }^{95}$ Durán Segura, "Viaje, experiencia y paisaje. La ruta Limón-San José”, 360-361.
} 
A las 10.30 a.m. llegamos a la estación de Juan Viñas y tomamos el tren para Limón [...] Ya desde El Guayabal se nos oscureció el sol: negros y más negros, y casi nada más que negros aparecieron ya a nuestra vista y nuestros oídos no percibían sino un inglés mal hablado, a la pedrada. También el olfato se dio cuenta de aquello. ${ }^{96}$

Observamos, como ese "olor de los otros" era un clave de representación. ${ }^{97}$ En sus relatos, los viajeros evidenciaban las características somáticas y culturales que imponían las corporalidades afrocaribeñas en los vagones del tren. En su relato de 1906, el viajero francés Saillard explica:

Después de un camino muy accidentado, llegamos a la llanura. A la frescura le sigue la humedad de los países tropicales. Los mosquitos y los negros invaden los vagones. "Querida, páseme su abanico", y es un bella negra que dirige, también en inglés puro, esta solicitud a su vecina, tan negra como ella misma. [...]

Otros alimentan a su familia, y es con su loro, con su mujer que regresan a su país después de dos años de labor. Su único defecto es envenenar los vagones con su olor. Las negras están vestidas de trajes de colores vivos y de telas muy ligeras. ${ }^{98}$

Un año más tarde, los ibéricos Segarra y Juliá relatan que el tren avanzaba lentamente dejando en las paradas "su carga de paquetes, de fardos, de viajeros entre los cuales se cuentan, como casi chocantes excepciones, muy pocos ejemplares de la raza blanca". ${ }^{99}$ Los periodistas españoles realizan una interesante narración de la vivencia experimentada en el interior de del ferrocarril:

Durante dos horas de viaje y tres horas distribuidas en innúmeradas paradas de algunos minutos, no oímos una docena de voces castellanas.

Nuestros compañeros de coche son casi todos negros, y hablan en inglés.

La exigua minoría de los viajeros blancos son yankis, y también hablan en inglés:

Negros astrosos, de catadura innoble, de un negro bruñido ó mate, de varia densidad de pavonadura; y negros francamente simpáticos, de facciones casi correctas, pulcros y aseados, de apostura elegante, asandwichados entre holandas y piqués relucientes de almidón...Y negras muy compuestas, vistiendo crugientes trajes claros con mucho encaje y mucho volante, cargadas de cadenillas y dijes y broches de oro, oliendo á esencias finas ó á patchoulí barato: las viejas, mascando tagarninas apestosas, entre sus quijadas, salientes y armadas de dentones bovinos; las jóvenes, claqueando la lengua discretamente, en el regodeo paladial de hartarse de confites y caramelos, ó fumando los inverosímiles cigarrillos á la moda del país: una toma de picadura liada en papel

\footnotetext{
${ }^{96}$ Durán Segura, "Viaje, experiencia y paisaje. La ruta Limón-San José”, 360.

${ }^{97}$ Sobre esta temática véase: Jean-Pierre Albert, "L'odeur des autres, à propos de quelques stéréotypes", en Böetsch, Hervé y Rozenberg, Corps normalicé, 77-86.

${ }^{98}$ Trad. nuestra. Rodolphe Saillard, "En traversant Costa Rica”, 538. Una versión de la traducción de este fragmento del relato aparece en otro artículo sobre el tema: Durán Segura, "Viaje, experiencia y paisaje. La ruta Limón-San José”, 361.

${ }^{99}$ Cursivas originales. Segarra y Juliá, Excursión por América: Costa Rica, 64,
} 
amarillo, -grueso como el papel de envolver fideos;- y que nos recordaban, con la melancolía de las nostalgias irremediables, el primer pitillo fumado clandestinamente: $[\ldots]$

Y -decíamos del bello sexo del coche- negras viejas y negras jóvenes, tan orondas y elegantonas, luciendo sobre sus cortas pelucas de etíope los sombreros más colosales y vistosos que jamás salieron de la fantasía de una modista de manicomio...Y rapados misters de porte sugestivamente desenfadado, la chaqueta al hombro, la camisa llena de abolladuras bajo la presión de los tirantes, rumiando entre ellos inarticuladas gangosidades.

Todos, la mayoría negra y la minoría blanca, todos expresándose en inglés, riendo en inglés, comportándose en inglés, y desdeñando en inglés á los que no gastábamos de inglés, ni el punto de los calcetines. ${ }^{100}$

Pero no solamente la percepción de la "otredad" se manifiesta en los vagones del tren, sino también en el paisaje externo que acompaña el recorrido del tren. H. R. Blaney indica en 1900: "Corriendo paralelamente al mar, el ferrocarril pasa a través de pequeños pueblos de negros jamaiquinos colocados en intervalos a lo largo de la línea". ${ }^{101}$ En el sentido de la ruta de Limón a San José, el norteamericano H. C. Pearson, por su parte, indica igualmente en 1906:

A las 10:30 abordamos el tren que debía llevarnos al interior, y recorrió veinte millas por un país plano, pantanoso donde incluso el costarricense nativo no puede vivir, pero donde el negro de Jamaica prospera y encera la grasa. A intervalos a lo largo del ferrocarril había pequeños grupos de chozas construidas sobre zancos para preservarlas del fango negro, techadas con chapas ondulas o hojas de palma, y lleno a desbordarse de súbditos de ébano de su majestad el rey Eduardo VII. Las cabezas de las familias que llaman estas chabolas, casas, eran en gran parte peones de las plantaciones de banano de la United Fruit Company. ${ }^{102}$

Esta imagen del paisaje inundado de corporalidades afrodescendientes será recurrente. El belga y famoso periodista en Francia, Maurice de Waleffe (1874-1946), ${ }^{103}$ cuyo nombre verdadero era Maurice Eugène Hubert Cartuyvels, ${ }^{104}$ con el objetivo de asistir a las fiestas que van a marcar la inauguración de la Corte Centroamericana de Justicia en San José de Costa Rica en 1908, sale de Panamá y se embarca en Colón en un barco frutero dirigido por un capitán noruego y donde se encuentra que una cabina que también estaba ocupada por tres chinos. ${ }^{105}$ El autor, cuya obra es traducida en

\footnotetext{
${ }^{100}$ Cursivas originales. Segarra y Juliá, Excursión por América: Costa Rica, 67-69. Un parte de este pasaje también es mencionado por: Durán Segura, "Viaje, experiencia y paisaje. La ruta Limón-San José”, 360.

${ }^{101}$ Citado por: Durán Segura, "Viaje, experiencia y paisaje. La ruta Limón-San José”, 359. Véase en original: Blaney, The Golden Caribbean, 49.

${ }^{102}$ Trad. nuestra. Pearson, What I saw in the Tropics, 186.

${ }^{103}$ Un autor erróneamente señala que "Maurice Waleffe, aventurero francés en 1912": Durán Segura,

"Viaje, experiencia y paisaje. La ruta Limón-San José", 359. No obstante, como hemos apuntado era belga y su visita fue más temprana.

${ }^{104}$ Maurice E. H. Cartuyvels había nacido en "les Waleffes”, de ahí su nombre de autor.

${ }^{105}$ Maurice de Waleffe, Les Paradis de l'Amérique centrale (Paris: Bibliothèque Charpentier, 1909), 122-128.
} 
Londres en inglés en 1911, ${ }^{106}$ tras su llegada a Limón, pasa la aduana, remunera a los cargadores de sus maletas, paga el ferrocarril y se acomoda en el vagón que lo dirigirá a San José. Waleffe recrea el ambiente exótico y selvático de las orillas del mar que transita el ferrocarril y nos sumerge en el mundo afrocaribeño:

Mientras tanto, después de que Costa Rica se convirtió en el principal proveedor de bananos de los Estados Unidos, -al punto que una compañía de barcos fruteros, creada expresamente, ¡transporta un millón de "racimos" al mes!- los plantadores estadounidenses trajeron algunos negros de Jamaica y les han construido, a lo largo de la vía férrea, casitas de palastro, de donde estos grandes negros de alma infantil ven pasar el tren riendo a carcajadas [...] $\mathrm{Y}$ el paso del tren hace acudir a pelotones de negritos todos desnudos, con el vientre abultado; chapotean bajo la lluvia tibia, nos sacan la lengua, nos arrojan cáscaras de banano, mientras que sus madres llevan sobre la cabeza canastas con piñas que ellas nos ofrecen con una amplia sonrisa. ${ }^{107}$

Un temor manifiesto en la obra de Waleffe -en su condición de europeoes la presencia de los "yankis" que habían adquirido los "bosques malsanos y casi intransitables" por "un buen precio", la readquisición de la vía férrea, la importación de "negros de Jamaica", el establecimiento de "un servicio directo de barcos fruteros con Nueva Orleans, y el cultivo de banano se ha vuelto un negocio formidable". ${ }^{108}$ Charles William Domville-Fife en una obra de 1913 sobre Guatemala parece retomar los criterios de Waleffe a quien menciona entre sus fuentes:

Desde el desarrollo de Costa Rica como un estado que cultiva banano, los plantadores americanos han traído una cantidad de negros de Jamaica. Cuando usted viaja a San José hoy, usted puede ver a estos negros parados al lado de la línea delante de sus chozas que la fecundidad tropical tiene ya emparradas por altas hierbas y palmas plumosas. Cuando el tren pasa, los grandes hombres negros lo saludan riendo a carcajadas, tan infantilmente felices como los gritos de los pequeños niños desnudos, quienes, asomando sus lenguas, saludan al viajero con una ducha de cáscaras de banana. ${ }^{109}$

De similar manera que M. de Waleffe, por esos años, el conde francés geógrafo, americanista, arqueólogo y explorador, Alexis Antoine Maurice de Périgny (1877-1935) -conocido simplemente como Maurice de Périgny-, comenta sobre la importante superficie dedicada al cultivo de bananos en el Caribe y como los terrenos aledaños a la línea del ferrocarril han sido "acaparados por la gran compañía estadounidense, la United Fruit Co, también matrona del ferrocarril”. ${ }^{110}$ Así, el francés

\footnotetext{
${ }^{106}$ Maurice de Waleffe, The Fair Land of Central America. Translated by Violette M. Montagu (London: John Long, Limited, 1911).

${ }^{107}$ Versión de: Quesada Pacheco, Entre silladas, 547-548. En el original: Waleffe, Les Paradis, 133

${ }^{108}$ Versión de: Quesada Pacheco, Entre silladas, 560; Waleffe, Les Paradis, 160-161.

109 Trad. nuestra. Charles W. Domville-Fife, Guatemala and the States of Central America (London-New York: Francis Griffiths-James Pott \& Company, 1913), 258.

${ }^{110}$ Versión de: Quesada Pacheco, Entre silladas, 576. En el original: Maurice de Périgny, (Le Comte de), Les cinq républiques de l'Amérique centrale (Paris: Pierre Roger et Cie. Éditeurs, s. f. (ca. 1911), 42.
} 
menciona que "las plantaciones están todas situadas en la Comarca de Limón, en terrenos medio pantanosos, poco salubres, y donde solo resisten los negros venidos de Jamaica". ${ }^{111}$ Con una impresionante similitud a la descripción de Waleffe encontramos la impresión del conde que llega a Puerto Limón en agosto de 1909 y que se dirige a la capital:

Se sigue a lo largo del mar algún tiempo, luego se entra en la selva, y entonces luce todo el esplendor de una vegetación tropical, el tallo grueso y vivaz de las palmeras de toda clase, plantas de hojas largas y diversas, coloreadas de rojo y amarillo.

En seguida se atraviesa la región de los bananales, sembrados regularmente en largas filas paralelas. Cerca de las estaciones, aparecen pequeñas casas de madera, construidas sobre postes, cuadradas, con un techo cubierto de hojas de zinc y una plataforma sobre la cual unos negros, con aire de indolentes, ríen con una risa larga y estúpida. Toda esta región les pertenece, no se ve más que a ellos y solo saben hablar inglés, ¡y qué inglés! ${ }^{112}$

Era la tierra de los "negros" y del inglés. Por su parte, el autor, periodista y hombre de negocios británico William Henri Koebel (1872-1923) describe en 1917 que cuando "el tren comienza a dejar los niveles bajos de la llanura, las plantaciones de banano, manejadas por negros jamaicanos, aparece a los lados de la línea, cada peón oscuro proveído de su pequeña chabola de chapa ondulada". ${ }^{113}$ Los esposos Calvert en 1917 indicaban sobre esos espacios:

Las cabañas ocupadas por los obreros negros se arracimaban alrededor de las estaciones, a veces solo dos o tres juntas, en otros lugares formando pequeñas aldeas. Cada casa contenía solo una o dos habitaciones; el exterior solía estar encalado, los techos eran de paja o de hierro galvanizados corrugado. ${ }^{114}$

De igual manera, otro norteamericano, el historiador Dana Gardner Munro (1892-1990), quien sería una autoridad en relaciones internacionales entre Estados Unidos y Latinoamérica y que llega a Centroamérica en julio 1914 becado por el Carnegie Endowment for International Peace para efectuar su investigación doctoral, explica en su publicación de 1918 que "a todo lo largo del ferrocarril y de sus numerosos ramales, se han desarrollado comunidades anglohablantes de estadounidenses y negros jamaiquinos". ${ }^{115}$ Por su lado, L. E. Elliot también señala que: "A poca altura, una región pantanosa, sigue por casi 20 millas; con la línea lindan las viviendas de negros, pequeñas chozas ociosas construidas de madera, sin pintar, con su manojo de bananos y naranjas en la puerta desvencijada" ${ }^{116}$ Asimismo, en 1926, F. G. Carpenter explicaba:

\footnotetext{
${ }^{111}$ Versión de: Quesada Pacheco, Entre silladas, 576. En el original: Périgny, Les cinq républiques, 42.

${ }^{112}$ Versión de: Quesada Pacheco, Entre silladas, 577. En el original: Périgny, Les cinq républiques, 44.

${ }^{113}$ Trad. nuestra. W. H. Koebel, Central America (London: Adelphi Terrace, 1917), 233.

${ }^{114}$ Traducción de: Durán Segura, "Viaje, experiencia y paisaje. La ruta Limón-San José”, 360.

115 Dana Gardner Munro, Las cinco repúblicas de Centroamérica. Desarrollo político y económico y relaciones con Estados Unidos. Estudios introductorios de Fabrice E. Lehoucq e Iván Molina Jiménez (San José, C.R.: Editorial de la Universidad de Costa Rica, Plumsock Mesoamerican Studies, 2003), 197.

116 Trad. nuestra. L. E. Elliot, Central America. New Paths in Ancient Lands (New York: Dodd, Mean and
} 
Viven [los "negros de Jamaica"] en pequeños pueblos esparcidos aquí y allá a largo de la línea del ferrocarril, y normalmente, tienen una parcela de tierra en las que cultivan parte de su comida. Los oficiales y los capataces son blancos, y las posiciones de responsabilidad están ocupadas en su mayor parte por americanos envíados aquí por los Estados Unidos". ${ }^{117}$

Entre 1916 y 1917, el estadounidense Hamilton Mercer Wright (1875-1954), nacido en New Haven (Connecticut), licenciado en derecho por la Universidad de Colorado, periodista que ocupó diversos cargos políticos y diplomáticos en Florida, Puerto Rico, Chile y Venezuela, viajó a América Central para escribir artículos para la revista The Panamerican Union. En 1917, H. M. Wright publica un artículo en el que relataba una breve estancia en Costa Rica durante la cual cruzó el país de costa a costa utilizando el ferrocarril. H. M. Wrigth se ocupa de describir el recorrido antes del ascenso hacia el Valle Central y siempre anota la presencia de afrocaribeños:

Después de las primeras 35 millas de Puerto Limón el ferrocarril trepa gradualmente por los cerros. Una región con ondulaciones, haciendas, pastizales marcados por árboles inmensos llenos de musgo, lagunas ocasionales reflejando sus alrededores y poblados de naturales de Jamaica son la característica del paisaje. Luego viene la abrupta transición a otro mundo; el viaje precipitado hacia la altiplanicie. ${ }^{118}$

En 1926, el periodista, corresponsal y editor estadounidense Wallace McGrath Thompson (1883-1936) -de ascendencia escocesa y originario de Kansastransmite las percepciones de su viaje ante de llegar a Cartago:

Toma [el tren] su salida a lo largo de las orillas del mar, una playa cubierta de líneas de árboles de coco y banano como podemos ver a nuestra derecha, y a nuestra izquierda, un bello río que murmulla corre paralelo al océano, y bordeando las arboledas de banano y coco. Entonces bosques y tierras de banano y negros; negros individualmente, en bandas, en chozas en zancos, en pueblos en zancos, -por todas partes. Y ningún costarricense de ningún matiz o color. Todo esto es la tierra de la United Fruit Company, y el trabajador es de Jamaica y otras islas de las Antillas británicas, trabajador contratado que viene bajo la protección del gobierno británico [...] El cinturón negro y el cinturón de bananos suben juntos, primero a través de la baja llanura costera, se ve una ruptura de los bananos provocada por los cocoteros, más tarde por las plantaciones de cacao, con los granos marrones de chocolate secándose en marcos en frente de las chozas entre las flores que los negros han plantado. Después las arboledas de banano se ven interrumpidas por campos más amplios de frijoles y patatas y pequeñas parcelas de maíz en las laderas, $\mathrm{y}$, por último, lejos en las colinas, por las primeras plantaciones de café. Pero el cinturón negro nunca se quiebra; ni una sola vez a lo largo del paseo del día,

Company, 1925), 219.

${ }^{117}$ Trad. nuestra. Carpenter, Lands of the Caribbean, 61.

${ }^{118}$ Cursiva del traductor. Versión de: Quesada Pacheco, Entre silladas, 612. En original: Hamilton M. Wright, "Through Costa Rica, The Magnificent, on a motor Car", Bulletin of the Pan American Union XVL: 588. 
hasta que alcancemos Cartago, la antigua capital, a una hora de San José, en las tierras altas. ${ }^{119}$

El mundo de las tierras bajas es esencialmente "negro". Como aprecia el investigador Durán Segura, el tren y el enclave bananero en Costa Rica permitieron a los extranjeros encuentros temporales con otras corporalidades, que a veces resultaron desagradables y que convocaron calificaciones negativas. ${ }^{120} \mathrm{Sin}$ embargo, no solamente los viajeros extranjeros hacían lecturas del mismo orden. Los nacionales también producían discursos bastante similares. En mayo de 1924, el Diario de Costa Rica publica en varios de sus números una crónica de un viaje a Limón. En dicha historia, el narrador transmite la imagen de la llegada a Limón:

Al tomar asiento en el coche del tren [saliendo de San José], un negro, servidor o brequero de él, nos hace suponer que vamos hacia lugares en los cuales se respiran otros aires distintos de los ticos [...] Entramos en otras regiones: todo cambia las personas y las cosas; la naturaleza y las poblaciones, hasta el idioma. Las casas son algo que un tiempo lo fueron y que hoy se conservan gracias a unas hojas de zinc carcomidas que es el único valor que tiene el inmueble.

Habitantes de esta clase de viviendas son negros de todas clases, tamaños yedades [sic]. Pero todos ellos feos, horribles; los hay monstruosos; moles inmensas, voluminosísimas, con pretensiones de mujer, q' [sic] más parecen hipopótamos o elefantes; unas viejísimas, muy arrugadas; otras jóvenes, emperifolladas. Y todos, ellas y ellos, feos y horribles, viejas y jóvenes, todos con un hedor especial que nuestro olfato rechaza desde el primer momento. ${ }^{121}$

Los relatos evocan acercamientos o choques con cuerpos diferentes, pero también recuerdan la existencia de espacios desemejantes. "Negros", "chozas" y "bananos" forman parte inherente de esa vertiente Caribe y las agrupaciones de afrodescendientes se observaban mejor en las estaciones. Turrialba era una de esas estaciones. Según la información de un letrero que continúa en colocado en la antigua estación de Turrialba (no utilizada desde los años 1990), la distancia de Turrialba a Limón era de 103,1 kilómetros y de Turrialba a San José de 63,6 kilómetros y la elevación de 625 m. ${ }^{122}$ Los esposos Calvert en sus relatos de 1909 también mencionan a Turrialba a la cual llaman la "estación de la piña"123 y exponen: "En Turrialba

\footnotetext{
119 Trad. nuestra. Wallace M. Thompson, Rainbow countries of Central America (New York: E. P. Dutton \& Company, 1926), 19.

${ }^{120}$ Durán Segura, "Viaje, experiencia y paisaje. La ruta Limón-San José”, 360.

${ }^{121}$ Fernando Balboa, “Croniqueando. Un viaje a Limón”, Diario de Costa Rica, 15 de mayo de 1924, 3.

122 "El tren pasó por Turrialba", CR Trenes, 2 de diciembre de 2010, http://crtrenes.blogspot.com/2010/12/ el-tren-paso-por-turrialba.html (25 de noviembre de 2020).

${ }^{123}$ Luko Hilje Quirós hace anotación en el relato de los Calvert sobre Turrialba: "En efecto, en el citado capítulo se explica que a la estación se le llamaba así porque los negros, y sobre todo las mujeres, subían a los vagones para vender piñas enteras a treinta centavos, o tajadas en cinco centavos. Lo simpático era observar numerosas cabezas de pasajeros proyectadas por las ventanillas, para poder consumir tan jugosa fruta, sin churretearse. Por cierto, muchos años después, el célebre geógrafo y botánico Henri Pittier, al referirse a las frutas del país, diría que "quien han comida una vez las [piñas] de Turrialba se queda con el agua en la boca al solo recuerdo" (Pittier, 1978)": Luko Hilje Quirós (comp.), Turrialba en la mirada de los viajeros (Cartago, C.R.: Editorial Tecnológica de Costa Rica, 2018), 476. Durán Segura menciona la
} 
todas las construcciones son de madera y predominan las casuchas, muchas de ellas habitadas por negros jamaiquinos". ${ }^{124}$ En 1907, los valencianos Segarra y Juliá señalan que en la línea del "Atlántico" hay dos estaciones con características muy propias: la de Turrialba y la de Cartago. Los viajeros sitúan a Turrialba a seiscientos metros sobre el nivel del mar y a Cartago a mil. La primera es descrita de la siguiente manera:

En la estación de Turrialba se repite para el viajero, por un instante, la visión del "espectáculo" que ya señalamos al hablar de la Línea Vieja. Queremos referirnos á la gente de color; que en Turrialba acometen á los pasajeros unas cuantas negras que con la mayor finura del mundo -y en inglés, por supuesto- ofrecen jugosas ostias de piña. Ni antes ni después os importunan los vendedores de la exquisita fruta tropical. Es este un privilegio, la característica de Turrialba. ${ }^{125}$

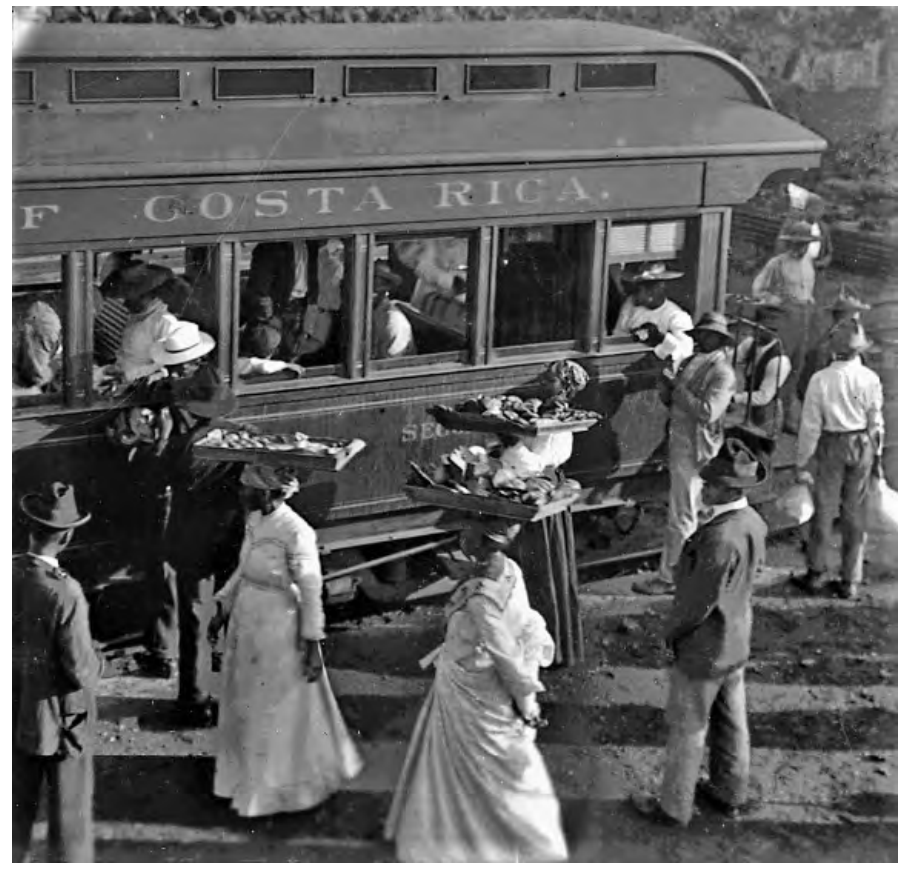

Figura 3. Afrocaribeños en una estación del ferrocarril al "Atlántico"

Fuente: "A typical passenger Train of Costa Rica, Central America". American Stereoscopic Company. New York. 1904. Colección personal.

Pero Turrialba también se convirtió en una estación emblemática no sólo por esa piña que se ofrecía los viajantes. Los folletos turísticos de la oficina de turismo costarricense en la década de 1930 destacan esta estación como un punto de separación de los ambientes en la geografía costarricense:

\footnotetext{
importancia de las estaciones y del comercio que se desarrolló a lo largo de todo el trayecto del ferrocarril: Durán Segura, "Viaje, experiencia y paisaje. La ruta Limón-San José", 361-362.

${ }^{124}$ Hilje Quirós, Turrialba, 476. En el original: Calvert y Calvert, A Year of Costa Rican, 245.

${ }^{125}$ Segarra y Juliá, Excursión por América: Costa Rica, 127-128.
} 
Turrialba, a propósito, es el límite de la "penetración" del negro y de ahí en adelante el recién llegado estará entre gente completamente costarricense; gente cuya bella tez testifica su inalterado origen europeo, culminando en San José, en una ciudad que no difiere enormemente, en cuanto a sus habitantes, de cualquier ciudad de Europa o América del Norte. ${ }^{126}$

La edición de 1946 de este fascículo turístico presenta la misma idea con otras palabras: "A partir de Turrialba, el recién llegado estará entre la gente totalmente costarricense cuya tez clara testifica su origen europeo no adulterado, culminando en San José, una ciudad no muy diferente en cuanto a sus habitantes de cualquier ciudad de Europa o América del Norte. ${ }^{127}$ Turrialba es el punto de cambio entre dos ambientes muy diferentes. Turrialba era un límite o antesala de un teatro de "homogeneidad" y "blancura".

Muchos historiadores han intentado encontrar, sin resultados, la fuente donde se pueda establecer la existencia de una interdicción de paso de los afrocaribeños al Valle Central. ${ }^{128}$ Sin embargo, diversos testimonios como también algunos documentos de la época - desde los años 1910- manifiestan que había un tipo de frontera para el paso de los afrocaribeños. Fernández Esquivel ha apuntado que la ley de 1934 -la restricción del paso del Caribe al Pacífico para trabajar en nuevas plantaciones bananeras- ha dado lugar para que muchas personas sostengan la creencia de que al negro se le prohibía trasladarse libremente por el territorio costarricense y que no se le permitía, por tanto, traspasar las fronteras de Turrialba hacia el interior. ${ }^{129}$ Senior Angulo piensa que se trató de una ley no escrita, una "ley fantasma". ${ }^{130}$ Ese recuerdo en la memoria colectiva es también expuesto por otra investigadora: "existe en la memoria de la comunidad limonense y de los costarricenses en general, una ley que prohibía a los negros pasar de Turrialba". ${ }^{131}$

\footnotetext{
126 Trad. nuestra. R.C.R., Sight Seeing [1934], 10; R.C.R, Sight Seeing [1935], 8-9; R.C.R, Sight Seeing [1936], 9. En el texto de 1936, se agrega la siguiente nota al final del mismo párrafo: "un rasgo en el que contrasta de forma muy favorable con otras grandes ciudades de América Latina": R.C.R, Sight Seeing [1936], 9 .

${ }^{127}$ Trad. nuestra. R.C.R., Sight Seeing [1946], 10.

${ }^{128}$ Harpelle, The West Indians, 92; Lara Putnam, “¿Qué tan ajenos, y qué tan extranjeros?: los antillanos británicos en América Central, 1870-1940”, en Nuestra herencia caribeña. Del olvido a la memoria 5, ed. Rina Cáceres (San José, C.R.: Cátedra de Estudios de África y el Caribe, Universidad de Costa Rica; UNESCO San José, Project supported by The Slave Route; Colegio de Licenciados y Profesores en Letras, Filosofía, Ciencias y Artes, 2011), 35; Bourgois, Banano, etnia, 141; Diana Senior Angulo, Diana, "La incorporación social en Costa Rica de la población afrocostarricense durante el siglo XX, 1927-1963" (Tesis Posgrado en Historia, Magister Scientiae en Historia). Universidad de Costa Rica, San José, 2007), 178-179, 203; Mitchel Allan Seligson, El campesino y el capitalismo agrario de Costa Rica (San José, C.R.: Editorial Costa Rica, 1980), 97; Carlos Meléndez Chaverri, "II. Aspectos sobre la inmigración jamaicana", en Carlos Meléndez Chaverri y Quince Duncan, El Negro en Costa Rica, 10ma. Ed., 1 reimp. (San José, C.R.: Editorial Costa Rica, 1993), 88-89.

${ }^{129}$ Franco Fernández Esquivel, “Aportación al estudio del negro en Costa Rica: participación política y discriminación racial, 1940-1975" (Tesis doctoral en Historia, Universidad Complutense de Madrid, Madrid, 1977), 367.

${ }^{130}$ Senior Angulo, "La incorporación”, 179.

${ }^{131}$ Reina Cristina Rosario Fernández, "Las identidades de la población de origen jamaiquino en el Caribe
} 
¿Qué relatan los viajeros al respecto de una limitación? El 21 de febrero de 1899, el arqueólogo, geógrafo y etnólogo alemán Karl Theodor Sapper Kutter (18661945) sale de San José Limón y explica: "En Turrialba comienza la población negra a superar la de los mestizos, y entre más se baja hacia la costa tanto más frecuente se ven negros y muy raro es ver un costarricense, con lo que a la vez aparece el inglés como lengua principal en el comercio, en detrimento del español". ${ }^{132}$ Puntualicemos que Sapper entendía en 1899 que "la altiplanicie central [estaba] compuesta de una población esencialmente blanca [...] Entre la población de la altiplanicie de Costa Rica llama la atención el porcentaje del elemento blanco". ${ }^{133}$ En 1924, sin embargo, Sapper se mostraba preocupado:

Si hace 25 años la zona predominante de la población negra y de la lengua inglesa era todavía estrecha, ella se extiende hoy por lo contrario, desde la costa hasta muy adentro del interior del país, y lo que es peor, la sangre negra ha penetrado en bastante proporción hasta en la capital, y ocupa ya un espacio considerable entre la extensa masa del pueblo. Cuando hace 25 años tuve en San José la impresión de que era una ciudad casi puramente europea, esto no es así para la ciudad actual pues el porcentaje de sangre negra salta a la vista, con una rápida mirada a los componentes de la multitud que transita por las calles. En las clases sociales altas, es cierto, no hay todavía esa mezcla de la sangre africana con los elementos blancos de la raza del país. [...] Lástima sería la pérdida de la pureza de la raza del más blanco de los Estados Tropicales. ${ }^{134}$

Podría interpretarse, según lo expuesto por Sapper, que se había transgredido un cierto "límite" y definido por el mismo alemán: Turrialba. En 1899, un cambio étnico en el paisaje entre el interior y el Caribe es observado por Sapper, pero en 1913, la famosa escritora y periodista australiana Winifred Lewellin James (18761941) -quien visita el país en aquella época- es mucho más explícita en cuanto los dos paisajes contrastantes y la definición de Turrialba como frontera "étnico-racial":

\begin{abstract}
A lo largo de la línea en ambos lados hay las chozas de los negros que pertenecen a los empleados en las fincas de banano. Cada estación es un municipio, y los chinos parecen ser los principales tenderos, aunque en cada distrito la Fruit Company tiene sus comisariatos y algunas estaciones que son aprovisionadas por el comisariato principal: en Limón para Costa Rica, en Santa Marta para Colombia, en Almirante para Panamá, etc. [...] Se dice que al negro le es permitido ir tan lejos como Turrialba y no más allá. El costarricense está muy orgulloso de la pureza de su sangre. Ciertamente cuando pasamos Turrialba el negro desaparece. El tren va lentamente, subiendo todo el camino. ${ }^{135}$
\end{abstract}

costarricense, 1872-1950", Diálogos. Revista Electrónica de Historia, número especial [9 congreso Centroamericano de Historia, Universidad de Costa Rica], 1249, https://revistas.ucr.ac.cr/index.php/ dialogos/article/view/31228 (25 de noviembre de 2020).

${ }^{132}$ Luko Hilje Quirós (comp.), Turrialba en la mirada de los viajeros (Cartago, C.R.: Editorial Tecnológica de Costa Rica, 2018), 420.

${ }^{133}$ Elías Zeledón Cartín (selecc.), Viajes por Costa Rica. Tomo II. Polakowsky-Bovallius-Seebach-Sapper (San José, C.R.: EUNED, 2014), 359, 368.

${ }^{134}$ Zeledón Cartín, Viajes por Costa Rica, 451.

${ }^{135}$ Trad. Nuestra. Winifred L. James, The Mulberry Tree (London: Chapman and Hall, Ltd. 1913), 202-203. 
Ese punto de cambio donde la población afrodescendiente comienza a ser escasa en el recorrido del ferrocarril también es sugerido en la guía turística de Costa Rica publicada por R. Villafranca Carazo en 1921. Cuando el autor comenta sobre la estación de Turrialba apunta:

El "País del banano" se ha quedado muy atrás y con él la mayor parte de los negros. De aquí en adelante hay vistas cada vez más extensivas del país, con colinas y valles, montañas y valles y, a menudo, distancias magníficas. Turrialba es la "estación de la piña". Los negros, principalmente mujeres, traen a los vagones de pasajeros tanto piñas enteras como también en rodajas. ${ }^{136}$

Turrialba era interpretado como el límite, pero también otros autores hablan de otro punto de división: Peralta. ${ }^{137}$ Esta estación se encontraba a unos kilómetros antes de llegar a Turrialba. Era una estación de tercera categoría fundada en 1890, pero que empezó a funcionar en 1910. Los Calvert precisaban sobre la particularidad de esta parada: "En Peralta había una media docena de cabañas habitadas por negros jamaiquinos, así como algunos edificios del ferrocarril, pero no más casas. Detrás de esos edificios se prolongaba una línea en forma de Y, para facilitar a las locomotoras revertir su ruta". ${ }^{138}$ Según un estudio de arqueología industrial, la estación fue uno de los puntos más importantes de la vía férrea entre Limón y San José desde el punto de vista operacional puesto que desde ésta las gradientes se elevaban y obligaban a los maquinistas a reducir el tonelaje para evitar la lentitud del tren y los accidente por lo que contaba un importante patio para los vagones y las mercancías. ${ }^{139}$ Los testimonios orales recogidos en dicha investigación entre 2013 y 2014 apuntan que Peralta era el último punto a donde podían llegar los afrocaribeños. ${ }^{140}$

Sin embargo, aunque pudo haber una restricción de tradición oral, los afrocaribeños sí lograban pasar a la Meseta Central. Ya en 1885, Alberto Masferrer cuenta la llegada del tren a la estación en San José -la estación del Atlántico- y recuerda "las zalamerías de los negros, que ofrecen: "manzanas-peras, que dan fuerza y salud". ${ }^{141}$ En 1904, el censo municipal de San José registraba 120 jamaiquinos ubicados especialmente en los distritos de Catedral y el Carmen. ${ }^{142}$ Alpízar Alpízar ha podido probar y analizar igualmente la presencia de jamaiquinos en el Cantón Central de San

\footnotetext{
${ }^{136}$ Trad. nuestra. Ricardo Villafranca Carazo, Costa Rican Guide For Tourists. Complete Pocket Edition (San José, C.R.: Imprenta Nacional, 1921), 41.

${ }^{137}$ Senior Angulo, "La incorporación”, 178; Bourgois, Banano, etnia, 141.

${ }^{138}$ Hilje Quirós, Turrialba, 294.

${ }^{139}$ Luis Andrés Arce Chavarría, "El ferrocarril al Atlántico. Distribución espacial y procesos socioeconómicos en las estaciones de Juan Viñas y Peralta (1870-1940): una aproximación desde la Arqueología Industrial" (Tesis de licenciatura en Antropología con énfasis en Arqueología, Universidad de Costa Rica, San José, 2015), 43.

${ }^{140}$ Arce Chavarría, "El ferrocarril", 47-48, 53, 167.

${ }^{141}$ Durán Segura, "Viaje, experiencia y paisaje. La ruta Limón-San José”, 362.

${ }^{142}$ Ronald Soto-Quirós, "Inmigración e identidad nacional en Costa Rica, 1904-1942. Los "otros" reafirman el "nosotros"” (Tesis de Licenciatura en Historia, Universidad de Costa Rica, San José, 1998), 355.
} 
José entre 1904 y $1950 .{ }^{143}$ También algunos investigadores anotan varios informes en los periódicos de los años veinte de excursiones turísticas de afrocaribeños en San José. ${ }^{144}$

Con respecto a algún tipo de legislación restrictiva en Costa Rica para la población afrodescendiente en su ingreso al país o en su movilidad interna sólo podemos constatar la legislación de 1862 que prohibía la colonización de las "razas africana y china"; la prohibición para ir a trabajar a la industria bananera del Pacífico para las "gentes de color" del Caribe de 1934 y; el reglamento de abril de 1942 que imposibilitaba la entrada de inmigrantes o transeúntes de "raza negra". ${ }^{145}$ Lo cierto del caso es que el punto de Turrialba representaba en algunos viajeros -como en la memoria colectiva de los costarricenses- una frontera simbólica o administrativa.

Las fronteras son signos y agentes de identidad y las identidades en sí mismas son ingredientes centrales en la construcción de fronteras. ${ }^{146}$ Había una frontera entre el espacio de la nación costarricense o "hogar nacional" - entendida como una "entidad con límites geográficos definidos que puede, pero que a menudo no corresponde a las fronteras del Estado"- ${ }^{147}$ y el espacio del enclave norteamericano poblado especialmente por afrocaribeños. En los relatos apreciamos la forja de esos paisajes racializados diferentes y la definición implícita o explícita de esa frontera simbólica. Muchísimos investigadores lo han constatado, el Caribe y, Limón en particular, es colocado al margen del imaginario social y de la identidad nacional costarricense en las estrategias políticas y narrativas nacionales, ${ }^{148}$ pero también es evidente en los relatos de extranjeros.

\section{A manera de conclusión}

En una época en la cual muchos afrocaribeños empezaban a adquirir la nacionalidad costarricense, ${ }^{149}$ en 1944, el intelectual costarricense Abelardo Bonilla

\footnotetext{
${ }^{143}$ Leidy Alpízar Alpízar, "Rompiendo el mito: inserción social de los jamaiquinos en el cantón Central de San José, entre 1904 y 1950" (Tesis, Posgrado en Historia, Maestría Académica en Historia. Universidad de Costa Rica, San José, 2017).

${ }^{144}$ Bourgois, Banano, etnia, 141.

${ }^{145}$ Ronald Soto-Quirós, "Discursos y políticas de inmigración en Costa Rica: 1862-1943”, Iberoamericana. América Latina-España-Portugal 5, no. 19 (septiembre 2005): 120, 126, 128.

${ }^{146}$ Hastings Donnan y Thomas M. Wilson, Borders: Frontiers of Identity Nation and State (New YorkOxford: Berg, 1999), 57.

${ }^{147}$ Trad. nuestra. Gidon Gottlieb, Nation against State. A new approach to Ethnic conflicts and the Decline of Sovereignty (New York: New York Council on Foreign Relation Press, 1993), 4.

${ }^{148}$ Diana Senior Angulo, "La conformación de Limón al margen del imaginario social e identidad nacional costarricense", en Puerto Limón (Costa Rica). Formas y Prácticas de auto/representación. Apuestas imaginarias y políticas/Puerto Limon (Costa Rica). Formes et pratiques d'auto/représentation. Enjeux imaginaires, culturels et politiques, eds. Q. Duncan Moodie y V. Lavou Zoungbo (Perpignan: Presses Universitaires de Perpignan, 2012), 31-44; Nicolas Batulet, "La nation costaricienne et les populations afro-descendantes: vers l'adoption du modèle multiculturaliste”, Naveg@mérica 23 (2019): 1-42, https:// dialnet.unirioja.es/servlet/articulo?codigo=7132615 (25 de noviembre de 2020).

${ }^{149}$ Diana Senior Angulo, Ciudadanía afrocostarricense. El gran escenario comprendido entre 1927 y 1963 (San José, C.R: EUNED-Editorial UCR, 2011); Mónica Pérez Granados, “Afrocaribeños en la legislación 1949 al 2014: de la condición jurídica y el ejercicio del derecho a la no discriminación”, en Relaciones interétnicas: afrodescendientes en Centroamérica, eds. J. H. Erquicia y R. Cáceres (San Salvador, El Salvador:
} 
Baldares (1898-1969) -catalogado como uno de los exponentes del "nacionalismo étnico metafísico", o sea, ese nacionalismo patrocinado desde los 1950 por el Estado costarricense que promovía una idea de la existencia de un "ser nacional" de "raza blanca" y que tenía al Valle Central como eje de imaginario de la vida nacional- ${ }^{150}$ publica El Valle nublado.${ }^{151}$

En dicha obra, el personaje principal -Fernando González- regresa a Costa Rica en 1939 después de muchos años de vivir en Europa. González toma el tren del Atlántico a las nueve de la mañana y llega a la estación a las cuatro de la tarde. El narrador relata los primeros pasos del tren que sigue la playa, los cacaotales y bananales en medio de un "calor terrible" y se sorprende de ver "el número de personas de color que vivían en aquella zona, en miserables rancherías y en tierras abandonadas, salvo por aquellas gentes que miraban estúpidamente el paso del tren". ${ }^{152}$ Luego, el narrador apunta que pasaban las horas, el paisaje cambiaba y la temperatura descendía hasta llegar a la "cuenca ondulante del Reventazón, verdadera estampa del trópico". En la novela, finalmente y después de un recorrido de "montañas altísimas y ornadas de vegetación lujuriosa", se puede leer:

El tren ascendía constantemente y la temperatura era cada vez más fresca a medida que se aproximaba la región blanca, la Meseta Central [...] La sensación de la altura y el frío hicieron reaccionar el ánimo montañés de Fernando. Estaba ya en la Meseta Central, que era el corazón y la vida del país y que sería su campo de actividad, y en ella sintió vibrar una emoción nueva que manaba de la fina y oculta fuente interior como un renacimiento de su naturaleza y de su orgullo. Aquel paisaje de altura, aquel clima delicioso, aquella tierra mansa y generosa, aquella modalidad natural y humana, llevaban en sí mismos las características especiales de la nación y el secreto del su orden democrático. Era, al fin, lo que él había esperado. Las gentes blancas, en cuyas caras creía reconocer matices familiares, los cafetales que en otros años habían formado parte de su vida. ${ }^{153}$

Sin duda, estos fragmentos del "ensayo en forma de novela"154 del intelectual costarricense tiene un parecido impresionante con los relatos de viajeros extranjeros. Es muy probable que el autor haya hecho lectura de algunos de ellos. Una prueba tal vez del alcance de estas obras de viajeros entre el público costarricense. Al igual que en los relatos de viaje, se ponía en evidencia ese importante contraste natural y cultural entre el altiplano central de clima subtropical de temperatura agradable y el trópico resplandeciente del Caribe centroamericano marcado históricamente por la presencia

\footnotetext{
Universidad Tecnológica de El Salvador, 2017), 242-259 y; Mónica María Pérez Granados, La construcción jurídica de la población afrocaribeña costarricense (1940-2014) (San José, C.R.: Editorial UCR, 2018).

${ }^{150}$ Alexander Jiménez Matarrita, El imposible país de los filósofos: el discurso filosófico y la invención de Costa Rica (San José, C.R.: Editorial de la Universidad de Costa Rica, 2005), 87, 181, 205.

151 Sobre esta obra véase el siguiente artículo: Mariannick Guennec, "El Valle nublado d'Abelardo Bonilla. La définition de l'identité nationale costaricienne à travers l'opposition entre culture populaire et culture savante", Amerika. Mémoires, identités, territoires 6 (2012), https://journals.openedition.org/ amerika/3159?lang=en (25 de noviembre de 2020)

${ }^{152}$ Abelardo Bonilla, El Valle nublado. 2da. Edición (San José, C.R.: EUNED, 1990), 30.

${ }^{153}$ Bonilla, El Valle nublado, 30-32.

${ }^{154}$ Bonilla, El Valle nublado, 11.
} 
africana y afrocaribeña creciente, por las influencias hegemónicas y, particularmente, de los Estados Unidos.

Como señalaba D. G. Munro en 1918: "Para el centroamericano, la costa es casi un país extranjero". ${ }^{155}$ La Costa Rica "blanca" tenía su espacio y representaba un paisaje claramente definido. El Caribe costarricense formaba un perfecto recurso simbólico de oposición que permitía consolidar el discurso "costarricense". Limón, la "Banana Land", era junto con los territorios indígenas y algunas zonas guanacastecas, parte de esas franjas marginales que, aunque estaban dentro de las fronteras políticas del Estado costarricense, que formaban parte de la geografía física nacional y estadísticamente contaban para muchos aspectos, no pertenecían realmente a la Nación. J. Pakkasvirta considera que desde los años 1880 el Caribe empezó a significar "la otredad, junto con otros extranjeros, "indios", "gringos", "chinos" o "negros". Especialmente el negro llegó a ser la "sombra del banano". ${ }^{156}$ El mismo autor explica claramente el conflicto identitario: "La imagen de Costa Rica siguió siendo blanca y progresista en el imaginario nacional. La nación era el Valle Central, y a veces, Puntarenas y Guanacaste. Limón -"la ciudad negra"- no existía en el imaginario nacional-territorial. [...] Sin duda, la población negra de la Costa Atlántica era un problema para la imagen homogénea, blanca y progresista de Costa Rica". ${ }^{157}$

A. Leeds en una reflexión sobre Limón y las fronteras de la "blancura" considera que Limón tuvo un papel de un "outsider-within" (un extranjero-dentro de) y manifiesta que Limón presentó una frontera, tanto racial como geográfica, en el imaginario nacional costarricense. ${ }^{158}$ De toda evidencia, los relatos permiten forjar una trama de dos paisajes racializados: el "caribeño", especialmente afrodescendiente y lo "costarricense", esencialmente imaginado como europeo. Había una estrategia de racialización y colorización de los espacios y sus cuerpos. El flujo que se producía en el marco de la ruta ferroviaria permitía a los autores dibujar etnopaisajes o paisajes étnicos: un etnopaisaje homogéneo -una supuesta homogeneidad cultural, lingüística y fenotípica-y estable en el Valle Central-y otro etnopaisaje más fluido y menos estable conformado por diversos grupos étnicos, pero especialmente cuerpos afrocaribeños. Pero más aún, a través de la descripción meticulosa del recorrido del ferrocarril entre Limón y San José, se logra fraguar la frontera simbólica entre ambos espacios -ya sea Turrialba o Peralta-. Los escritores de relatos son voces "racializadoras". Los relatos de viaje se convierten en herramientas para la consolidación de divisiones o fronteras étnico-raciales. Los testimonios de viajeros extranjeros coinciden perfectamente con el relato nacional y, contribuyen a alimentar una narrativa nacionalista, xenofóbica y racialista.

\footnotetext{
${ }^{155}$ Munro, Las cinco repúblicas, 69.

${ }^{156}$ J. Pakkasvirta, “El Caribe, la 'otra' nación: el caso de Costa Rica”, en El Caribe centroamericano, eds. J. Pakkasvirta y K. Wilska (Helsinki, Finlandia: Publicaciones del Renvall Institute, 2005), 14.

${ }^{157}$ Pakkasvirta, "El Caribe”, 18.

${ }^{158}$ Asia Leeds, "Representations of Race, Entanglements of Power: Whiteness, Garveyism, and Redemptive Geographies in Costa Rica, 1921-1950" (Dissertation, Doctor of Philosophy in African Diaspora Studies, University of California, Berkeley, U.S.A, 2010), 21-22.
} 
Paisajes racializados y fronteras identitarias en Costa Rica:relatos de viajeros y el ferrocarril...

\section{Bibliografía}

\section{Fuentes primarias}

Diversos periódicos 1900-1934 (Hemeroteca. Biblioteca Nacional de Costa Rica)

Balboa, Fernando. "Croniqueando. Un viaje a Limón”. Diario de Costa Rica, 15 de mayo de 1924, 3.

Doctor Sisawath, “Crónicas porteñas. Desde Limón”, La Prensa Libre, 19 de junio de 1914, 4.

\section{Censos y documentos oficiales (Gobierno de Costa Rica)}

R.C.R. Censo de la República de Costa Rica (1883). San José, C.R.: República de Costa Rica, Ministerio de Economía, Industria y Comercio, DGEC, 1975.

R.C.R. Censo de población de Costa Rica. 11 de mayo de 1927. San José, C.R.: Ministerio de Economía y Hacienda, Dirección General de Estadística y Censos, 1960.

R.C.R. Censo de Población. 1864. San José, C.R.: Imprenta Nacional, 1868.

R.C.R. Costa Rica. "The Heart of The Americas". The Tourist's Paradise. $2^{\text {nd }}$. Ed. San José, C.R.: National Tourist Board of Costa Rica, 1935.

R.C.R. Secretaria de Salubridad Pública y Protección Social. Departamento de Biodemografía. Aspectos Biodemográficos de la Población de Costa Rica. Informe correspondiente al año 1940. Presentado por el Dr. Pablo Luros. San José, C.R.: Imprenta Nacional, 1942.

R.C.R. Sight Seeing in Costa Rica. The Heart of the Americas. A Booklet of Useful Information. San José, C.R.: National Tourist Board of Costa Rica, ca. 1934.

R.C.R. Sight Seeing in Costa Rica. The Heart of the Americas. A Booklet of Useful Information. $3^{\text {rd }}$. Ed. San José, C.R.: National Tourist Board of Costa Rica, 1935.

R.C.R. Sight Seeing in Costa Rica. The Heart of The Americas. A Booklet of Useful Information. San José, C.R.: National Tourist Board of Costa Rica, 1946.

R.C.R. Sight Seeing in Costa Rica. The Heart of The Americas. A Booklet of Useful information. $4^{\text {th }}$ ed. (revised). San José, C.R: National Tourist Board of Costa Rica, C.R.: Imprenta Borrasé, 1936.

\section{Fuentes secundarias}




\section{Libros}

Adams, Frederick Upham. Conquest of the Tropics. Garden, City, New York: Doubleday, Page \& Company, 1914.

Appadurai, Arjun. La modernidad desbordada. Dimensiones culturales de la globalización. Montevideo, Uruguay/Buenos Aires, Arg.: Ediciones Trilce S.A./ Fondo de Cultura Económica de Argentina, S.A., 2001 [primera ed. en inglés 1996].

Banton, Michael. Racial Theories. Second edition. New York: Cambridge University Press, 1998.

Blaney, Henry R. The Golden Caribbean. Boston: Lee \& Shepard, Publishers, 1900.

Blaney, Henry R. The Golden Caribbean. Boston: Lee \& Shepard, Publishers, 1900.

Boëtsch, Gilles, Christian Hervé y Jacques J. Rozenberg (eds.). Corps normalisé, corps stigmatisé, corps racialisé. Bruxelles: De Boeck Supérieur, 2007.

Bonnemaison, Joël y Luc Cambrezy (dir.). La Nation et le territoire, le territoire, lien ou frontière? Tome 2. Paris: L'Harmattan, 1999.

Bourgois, Philippe. Banano, etnia y lucha social en Centro América. San José, C.R.: DEI, 1994.

Buraschi, Daniel y María José Aguilar Idáñez. Racismo y antirracismo. Comprender para transformar. Ciudad Real: Ediciones de la Universidad de Castilla-La Mancha, 2019.

Calvert, Amelia Smith y Philip Powel Calvert. A Year of Costa Rican Natural History. New York: The MacMillan Company, 1917.

Camacho Navarro, Enrique. Cómo se pensó Costa Rica. Imágenes e imaginarios en tarjetas postales: 1900-1930. México, D.F.: Universidad Nacional Autónoma de México, 2015.

Carpenter, Frank G. Lands of the Caribbean. Garden City/New York: Doubleday, Page \& Company, 1926.

Chomsky, Aviva. West Indian Workers and the United Fruit Company in Costa Rica, 1870-1940. Baton Rouge and London: Louisiana State University Press, 1996.

Crowther, Samuel. The Romance and Rise of the American Tropics. New York: Doublebay, Doran \& Company, Inc., 1929. 
Paisajes racializados y fronteras identitarias en Costa Rica:relatos de viajeros y el ferrocarril...

Desportes, M. Paysages en mouvement: transports et perception de l'espace, XVIIIeXXe siècle. Paris: Gallimard (Collection Bibliothèques des Histoires, Série illustrée), 2005.

Dobles Segreda, Luis. Indice bibliográfico de Costa Rica. Tomo Segundo. San José, C.R.: Imprenta Lehmann (Sauter \& Co), 1928.

Domville-Fife, Charle W. Guatemala and the States of Central America. LondonNew York: Francis Griffiths-James Pott \& Company, 1913.

Donnan, Hastings y Thomas M. Wilson. Borders: Frontiers of Identity Nation and State. New York-Oxford: Berg, 1999.

Eisner, G. Jamaica. 1830-1930. A study in economic growth. London: Manchester University Press, 1961.

Elliot, L. E. Central America. New Paths in Ancient Lands. New York: Dodd, Mean and Company, 1925.

Foster, Harry L. A gringo in Mañana Land. London: John Lane the Bodley Head Ltd., 1924.

González Vásquez, Fernando y Elías Zeledón Cartín. Crónicas y relatos para la historia de Puerto Limón. San José, C.R.: Ministerio de Cultura, Juventud y Deportes, Centro de Investigación y Conservación del Patrimonio Cultural, 1999.

Gottlieb, Gidon. Nation against State. A new approach to Ethnic conflicts and the Decline of Sovereignty. New York: New York Council on Foreign Relation Press, 1993.

Hanway, Nancy. Embodying Argentine. Body. Space and Nation in $19^{\text {th }}$ Century Narrative. Jefferson, Norh Carolina and London: Mc Farland \& Company, Inc. Publishers, 2003.

Harpelle, Ronald. The West Indians of Costa Rica, Race, Class, and the Integration of an Ethnic Minority. Kingston/Montreal/London/Ithaca: Ian Randle Publishers, McGill-Queen's University Press, 2001.

Hilje Quirós, Luko (comp.). Turrialba en la mirada de los viajeros. Cartago, C.R.: Editorial Tecnológica de Costa Rica, 2018.

James, Winifred L. The Mulberry Tree. London: Chapman and Hall, Ltd. 1913.

Jones, Chester Lloyd. Costa Rica and Civilization in the Caribbean. Madison: University of Wisconsin, 1935. 
Jones, Chester Lloyd. Costa Rica and Civilization in the Caribbean. Madison: University of Wisconsin, 1935.

Koebel, W. H., Central America. London: Adelphi Terrace, 1917.

Lambert de Sainte-Croix, A. Onze mois au Mexique et au Centre-Amérique. Paris: Librairie Plon, 1897.

Lever, E. A. Central America or, The land of the Quiches and Chontales. New Orleans: E. A. Brandao \& Co., Publishers, 1885.

Munro, Dana Gardner. Las cinco repúblicas de Centroamérica. Desarrollo político y económico y relaciones con Estados Unidos. Estudios introductorios de Fabrice E. Lehoucq e Iván Molina Jiménez. San José, C.R.: Editorial de la Universidad de Costa Rica, Plumsock Mesoamerican Studies, 2003.

Murillo Chaverri, Carmen. Identidades de hierro y humo. La construcción del Ferrocarril al Atlántico. 1870-1890. San José, C.R.: Porvenir, 1995.

Nogué, Joan (ed.). La construcción social del paisaje. Madrid: Biblioteca Nueva, 2007.

Pakkasvirta, J. ¿Un continente, una nación? Intelectuales latinoamericanos, comunidad política y las revistas culturales en Costa Rica y Perú (1919-1930). San José, C.R.: Editorial de la Universidad de Costa Rica, 2005.

Palmer, Frederick. Central America and its problems. New York: Moffat, Yard \& Co., 1913.

Pearson, Henry C. What I saw in the Tropics. New York: The India Rubber Publishing, Co., 1906.

Pector, Désiré. Les richesses de l'Amérique centrale. Guatemala, Honduras, Salvador, Nicaragua, Costa-Rica. Préface de M. E. Levasseur. Paris: Librairie Orientale \& Américaine E. Guilmoto, Éditeur, s.f. (ca. 1908).

Pector, Désiré. Les richesses de l'Amérique centrale. Guatemala, Honduras, Salvador, Nicaragua, Costa-Rica. Préface de M. E. Levasseur. Paris: Librairie Orientale \& Américaine E. Guilmoto, Éditeur, s.f. (ca. 1908).

Pérez Granados, Mónica María. La construcción jurídica de la población afrocaribeña costarricense (1940-2014). San José, C.R.: Editorial UCR, 2018.

Périgny, Maurice de (Le Comte de). Les cinq républiques de l'Amérique centrale. Paris: Pierre Roger et Cie. Éditeurs, s. f. (ca. 1911). 
Paisajes racializados y fronteras identitarias en Costa Rica:relatos de viajeros y el ferrocarril...

Putnam, George Palmer. The Southland of North America. New York-London: G. P. Putnam's Sons, 1914.

Putnam, Lara. The Company They Kept. Migrants and the Politics of Gender in Caribbean Costa Rica, 1870-1960. Chapel Hill and London: University of North Carolina Press, 2002.

Quesada Pacheco, Miguel Ángel. Entre silladas y rejoyas. Viajeros por Costa Rica de 1850 a 1950. Cartago, C.R.: Editorial Tecnológica de Costa Rica, 2001.

Riley, James C. Poverty and Life Expectancy. The Jamaican Paradox. New York: Cambridge University Press, 2005.

Ruhl, Arthur J. The Central Americans. New York-London: Charles Scribner's Sons, 1928.

Segarra, José y Joaquín Juliá. Excursión por América: Costa Rica. San José, C.R.: Imprenta de Avelino Alsina, 1907.

Seligson, Mitchell Allan. El campesino y el capitalismo agrario de Costa Rica. San José, C.R.: Editorial Costa Rica, 1980.

Senior Angulo, Diana. Ciudadanía afrocostarricense. El gran escenario comprendido entre 1927 y 1963. San José, C.R: EUNED-Editorial UCR, 2011.

The Pan American Union. Costa Rica. General Descriptive Data. Washington, D.C.: Government Printing Office, 1924.

Thompson, Wallace M. Rainbow countries of Central America. New York: E. P. Dutton \& Company, 1926.

Vargas Alvarado, Sussy. El Caribe limonense a través de la mirada y la obra de Hans Wimmer: 1903-1947. San José, C.R: Autora, 2018.

Viales Hurtado, Ronny J. Después del enclave. Un estudio de la Región Atlántica Costarricense. San José, C.R.: Editorial de la Universidad de Costa Rica, 1998.

Villafranca Carazo, Ricardo. Costa Rican Guide For Tourists. Complete Pocket Edition. San José, C.R.: Imprenta Nacional, 1921.

Waleffe, Maurice de. Les Paradis de l'Amérique centrale. Paris: Bibliothèque Charpentier, 1909.

Waleffe, Maurice de. The Fair Land of Central America. Translated by Violette M. Montagu. London: John Long, Limited, 1911. 
White, George W. Nation, State and Territory. Origins, Evolutions, and Relationships, Vol. 1. Lanham-Boulder-New York-Toronto-Plymouth, UK: Rownan \& Littlefield Publishers, Inc., 2007.

Whittaker, Sabas H. Africans in the Americas. Our Journey Throughout The World. New York, Lincoln (NE): Shangai, iUniverse, Inc., 2003.

Zeledón Cartín, Elías. Viajes por Costa Rica. Tomo II. Polakowsky-Bovallius-SeebachSapper. San José, C.R.: EUNED, 2014.Adams, Frederick Upham. Conquest of the Tropics. Garden, City, New York: Doubleday, Page \& Company, 1914.

\section{Capítulos de libro}

Albert, Jean-Pierre. "L'odeur des autres, à propos de quelques stéréotypes", en Corps normalisé, corps stigmatisé, corps racialisé. Editado por Gilles Boëtsch, Christian Hervé y Jacques J. Rozenberg. Bruxelles: De Boeck Supérieur, 2007, 77-86.

Guennec, Mariannick. "El Valle nublado d'Abelardo Bonilla. La définition de l'identité nationale costaricienne à travers l'opposition entre culture populaire et culture savante". Amerika. Mémoires, identités, territoires 6 (2012).

Harpelle, Ronald. "Zonas blancas": Comunidades de enclave norteamericanas en América Central”. En La negritud en Centroamérica: entre raza y raíces. Editado por L. Gudmundson y J. Wolfe. San José, C.R: EUNED, 2012, 405-434.

Hutchinson Miller, Carmen. The Province and Port of Limon: metaphors for AfroCosta Rican black identity. Heredia, C.R.: EUNA, 2015.

Jiménez Matarrita, Alexander. El imposible país de los filósofos: el discurso filosófico y la invención de Costa Rica. San José, C.R.: Editorial de la Universidad de Costa Rica, 2005.

Molina Jiménez, Iván. "Limón blues: Una novela de Anacristina Rossi". En Représentations des Noir(e)s dans les pratiques discursives et culturelles en Caraïbe. Editado por V. Lavou Zoungbo. Perpignan: Travaux du GRENAL et collaborations, Centre de Recherches Ibériques et Latino-Américaines, Université de Perpignan Via Domitia, 2006, 167-172.

Pakkasvirta, J. "El Caribe, la 'otra' nación: el caso de Costa Rica”. En El Caribe centroamericano. Editado por J. Pakkasvirta y K. Wilska. Helsinki, Finlandia: Publicaciones del Renvall Institute, 2005, 13-21.

Pérez Granados, Mónica. “Afrocaribeños en la legislación 1949 al 2014: de la condición jurídica y el ejercicio del derecho a la no discriminación". En Relaciones interétnicas: afrodescendientes en Centroamérica. Editado por J. H. Erquicia y R. Cáceres. San Salvador, El Salvador: Universidad Tecnológica de El Salvador, 2017), 242-259. 
Putnam, Lara. “¿Qué tan ajenos, y qué tan extranjeros?: los antillanos británicos en América Central, 1870-1940”. En Nuestra herencia caribeña. Del olvido a la memoria 5, ed. Rina Cáceres. San José, C.R.: Cátedra de Estudios de África y el Caribe, Universidad de Costa Rica; UNESCO San José, Project supported by The Slave Route; Colegio de Licenciados y Profesores en Letras, Filosofía, Ciencias y Artes, 2011.

Putnam, Lara. "Foráneos al fin: La saga multigeneracional de los antillanos británicos en América Central, 1870-1940". En La negritud en Centroamérica: entre raza y raíces. Editado por L. Gudmundson y J. Wolfe. San José, C.R: EUNED, 2012, 367-403.

Richardson, Bonham C. "The Migration Experience". En General History of the Caribbean, Volumen V. The Caribbean in the Twentieth Century. Editado por B. Bridget. Paris: UNESCO Publishing; London: MacMillan Caribbean, 2004, 434464.

Senior Angulo, Diana. "La conformación de Limón al margen del imaginario social e identidad nacional costarricense". En Puerto Limón (Costa Rica). Formas y Prácticas de auto/representación. Apuestas imaginarias y políticas/Puerto Limon (Costa Rica). Editado por Q. Duncan Moodie y V. Lavou Zoungbo. Perpignan: Presses Universitaires de Perpignan, 2012, 31-44.

Soto-Quirós, Ronald. "De Limón à San José: un voyage vers l'espace de la nation costaricienne". En La mer Caraïbe, espace de migrations. Editado por Michèle Dalmace. Bordeaux: Presses Universitaires de Bordeaux (PUB), Collection de la Maison des Pays Ibériques, Séries Amériques/AMERIBER (CARHISP), 2012, 233-260.

Viales Hurtado, Ronny J. "La reconceptualización del "enclave” bananero desde la perspectiva de la historia económica. Una propuesta a partir del caso de la región Atlántica (Caribe) costarricense entre 1870 y 1950”. En El Caribe centroamericano. Editado por J. Pakkasvirta y K. Wilska. Helsinki, Finlandia: Publicaciones del Renvall Institute, 2005, 32-71.

Viales Hurtado, Ronny J. “La segmentación socio-racial en el capitalismo periférico. Globalización, circulación de personas, transnacionalismo y mercado de trabajo en el "enclave" bananero de Costa Rica, 1899-1930". En Historia de las desigualdades étnico-raciales en México, Centroamérica y el Caribe (siglos XVIII-XXI). Editado por C. Lacaze, R. Soto-Quirós, R. J. Viales Hurtado. San José, C.R.: Universidad de Costa Rica, Vicerrectoría de Investigación: Centro de Investigaciones Históricas de América Central, en colaboración con AMERIBER, Université Bordeaux Montaigne (Bordeaux), 2019, 93-128. 


\section{Artículos de revistas}

Biolley, Pablo. "Bibliografía. Obras publicadas en el extranjero acerca de la República de Costa Rica durante el siglo XIX. Notas compiladas y ordenadas por Pablo Biolley", Revista de Costa Rica en el siglo XIX. Tomo Primero. San José, C.R.: Tipografía Nacional (1902): 363-404.

Durán Segura, Luis Armando. "Viaje, experiencia y paisaje. La ruta Limón-San José en los relatos de extranjeros (Costa Rica, 1880-1940)". Ería. Revista Cuatrimestral de Geografia XXXVIII, 2 (2018): 345-365.

Durán Segura, Luis. "Viaje, experiencia y paisaje. La ruta Puntarenas-San José en los relatos de extranjeros (Costa Rica, 1840-1880)". On the w@terfront [RCUB] 60, 11 (2018): 3-38.

Echeverri-Gent, Elisavinda. "Forgotten Workers: British West Indians and the Early Days of the Banana Industry in Costa Rica and Honduras". Journal of Latin American Studies 24, 2 (1992): 275-308.

Elliot, L. E. "Towns of Costa Rica". The Pan American Magazine XIV, no. 2 (junio 1912): 23-35.

Elliot, L. E. "Towns of Costa Rica". The Pan American Magazine XIV, 2 (1912): 23-35.

Huertas, Gerardo Peraldo y Ernesto Rojas Cedeño. "La deslizable historia del ferrocarril al Caribe de Costa Rica". Anuario de Estudios Centroamericanos 24, 1-2 (1998): 97-128.

Popenoe, Paul B. "Costa Rica, Land of the Banana". The National Geographic Magazine XLI, 2 (1922): 201-222.

Putnam, Lara. "Contact Zones: Heterogeneity and Boundaries in Caribbean Central America at the Start of the Twentieth Century". Iberoamericana. América LatinaEspaña-Portugal 6, 23 (2006): 113-126.

Quesada Monge, Rodrigo. "Ferrocarriles y crecimiento económico: el caso de la Costa Rica Railway Company, 1871-1905”. Anuario de Estudios Centroamericanos 9, 1 (1983): 87-119.

Rasor, W. W. "Railroads in Costa Rica". The Pan-American Magazine XII, 1 (1911): 386-388.

Ruhl, Arthur J. “Campaignig in Costa Rica”. The Outlook (1914): 35-40. 
Saillard, Rodolphe. "En traversant Costa Rica". Le Tour du Monde XII [Nouvelle série], 45 (1906): 530-540.

Soto-Quirós, Ronald. "“Y si el olor y el color de...": racismo en la Costa Rica de principios del siglo XX". Aguaita. Revista del Observatorio del Caribe Colombiano 17-18 (2008): 41-58.

Soto-Quirós, Ronald. "Desarrollo, étnica y marginalización: imágenes del puerto caribeño de Limón, Costa Rica (1838-1967)”. Études caribéennes 21 (2012).

Soto-Quirós, Ronald. "Discursos y políticas de inmigración en Costa Rica: 18621943”. Iberoamericana. América Latina-España-Portugal 5, 19 (septiembre 2005): 119-133.

Soto-Quirós, Ronald. "Imaginando una nación de raza blanca en Costa Rica: 18211914”. Amérique Latine: Histoire et Mémoire. Les cahiers ALHIM 15 (2008): 233-271.

Soto-Quirós, Ronald. "Un otro significante en la identidad nacional costarricense: el caso del inmigrante afrocaribeño, 1872-1926”, Boletín AFEHC 25 (2006): 1-32.

Viales Hurtado, Ronny J. “La región Atlántico-Caribe de Costa Rica: las imágenes de la construcción regional". Memorias. Revista digital de Historia y Arqueología desde el Caribe [año] 12, 30 (2016): 219-233.

Wright, Hamilton M. "Through Costa Rica, The Magnificent, on a motor Car". Bulletin of the Pan American Union XVL (1917): 577-599.

\section{Tesis, ponencias y otros}

Alpízar Alpízar, Leidy. "Rompiendo el mito: inserción social de los jamaiquinos en el cantón Central de San José, entre 1904 y 1950". Tesis, Posgrado en Historia, Maestría Académica en Historia. Universidad de Costa Rica, San José, 2017.

Arce Chavarría, Luis Andrés. "El ferrocarril al Atlántico. Distribución espacial y procesos socioeconómicos en las estaciones de Juan Viñas y Peralta (1870-1940): una aproximación desde la Arqueología Industrial". Tesis de licenciatura en Antropología con énfasis en Arqueología. Universidad de Costa Rica, San José, 2015.

Cuillerai, Marie y Marc Abélès. "Mondialisation: du géo-culturel au bio-politique". Anthropologie et Sociétés 26, 1 (2002): 11-28.

Fernández Esquivel, Franco. “Aportación al estudio del negro en Costa Rica: participación política y discriminación racial, 1940-1975". Tesis doctoral en Historia, Universidad Complutense de Madrid, Madrid, 1977.

Gudmundson, Lowell. “¿Prisioneros de enclave o forjadores de una precoz modernidad? Los afro-antillanos y el Atlántico en la historia centroamerica [sic: 
centroamericana]". En Nuestra herencia caribeña. Del olvido a la memoria 5. Editado por R. Cáceres. San José, C.R.: Cátedra de Estudios de África y el Caribe, Universidad de Costa Rica; UNESCO San José, Project supported by The Slave Route; Colegio de Licenciados y Profesores en Letras, Filosofía, Ciencias y Artes, 2011, 83-89.

Leeds, Asia. "Representations of Race, Entanglements of Power: Whiteness, Garveyism, and Redemptive Geographies in Costa Rica, 1921-1950". Dissertation, Doctor of Philosophy in African Diaspora Studies. University of California, Berkeley, U.S.A, 2010.

Meléndez Chaverri, Carlos. "II. Aspectos sobre la inmigración jamaicana". En Carlos Meléndez Chaverri y Quince Duncan. El Negro en Costa Rica, 10ma. Ed., 1 reimp. San José, C.R.: Editorial Costa Rica, 1993, 59-95.

Rosario Fernández, Reina Cristina. "Las identidades de la población de origen jamaiquino en el Caribe costarricense, 1872-1950". Diálogos. Revista Electrónica de Historia, número especial $\left[9^{\circ}\right.$ congreso Centroamericano de Historia, Universidad de Costa Rica] (2008): 1243-1268.

Soto-Quirós, Ronald. "Inmigración e identidad nacional en Costa Rica, 1904-1942. Los "otros" reafirman el "nosotros"”. Tesis de licenciatura en Historia, Universidad de Costa Rica, San José, 1998. 